\title{
Hutterite Colonies and the Cultural Landscape: An Inventory of Selected Site Characteristics
}

\author{
Simon M. Evans ${ }^{1}$ \\ Adjunct Professor \\ Department of Geography \\ University of Calgary \\ Peter Peller \\ Head, Spatial and Numeric Data Services \\ Libraries and Cultural Resources \\ University of Calgary
}

\begin{abstract}
Hutterite colonies are a growing and sustainable element in the cultural landscape of the Canadian Prairies and Northern Great Plains of the United States. Their increasing numbers do something to offset the disappearance of the smallest service centers on the plains. While the diffusion of these communities has been well documented, the morphology of the settlements has been less well studied. New technology makes it possible to remotely evaluate selected characteristics of almost all Hutterite colonies. This paper describes the differences, with respect to orientation, layout and housing types, both between the four clan groups and within the Dariusleut and Schmiedeleut. Here as in many other aspects of Hutterite culture, there are signs of change and increasing diversity.
\end{abstract}

\section{Keywords}

Hutterite colonies; Cultural landscape; Google Earth; Orientation; Layout; Housing types; Dariusleut; Lehrerleut; Schmiedeleut; Great Plains

Evans, Simon, and Peter Peller. 2016. "Hutterite Colonies and the Cultural Landscape: An Inventory of Selected Site Characteristics." Journal of Amish and Plain Anabaptist Studies 4(1):51-81. 


\section{Introduction}

Flying low from Calgary to Lethbridge, Alberta, and on to Great Falls, Montana, it is easy to pick out Hutterite colonies. Their relatively large and complex footprint is in marked contrast to that of neighbouring family farms. Colonies even show up clearly when viewed from the cruising altitude of a jet airliner. Their extensive bare 'work yards' between machine shops, the barns and the grain stores, stand out as white parcels in a textured sea of green agricultural land. Ironically, considering the passionate pacificism of the sect, their colonies, with their uniform geometric layouts, resemble small military establishments. Descending closer, banks of gleaming grain storage silos, neat gardens, and long low barns can be distinguished. Many colonies are surrounded by extensive feed corrals and lagoons to contain effluent from pig and chicken barns. Less easy to see, because it is often partially obscured by trees and shrubs, is the residential heart of the colony. This is the zone of nurture, where children play and adults sit and chat at the end of the day. The world of work, commerce, and contact with "the English" outsiders is discretely excluded. Several long multi-family dwellings frame a spacious court. A pattern of concrete pathways link these dwellings to the kitchen/dining room complex in which the community meets for meals three times a day. ${ }^{2}$

The Hutterites are a religious sect, an ethnic group, and a communal brotherhood; they possess a culture and an economy (Janzen and Stanton 2010; Katz and Lehr 2012). Among the many immigrant groups that have settled the plains of western North America, the Hutterites are unique in the degree to which they have resisted assimilation. They have retained their German language, their schools and socialization processes, their clothing and their life style. Their Anabaptist religious beliefs are the glue which has kept the brethren together, while their strict adherence to the principle of holding all things in common sets them apart from other Anabaptist groups like the Amish and the Mennonites (Kraybill and Bowman 2001). The Hutterites point with pride to their 400 years of history, but their pacificism and extreme views on the ordering of society led to several forced migrations within Europe. In 1874, threatened with conscription into the Russian army, the group fled the Ukraine and settled along the James River on the Dakota frontier of the United States (Hostetler 1974; Hofer 1982). There they enjoyed some 40 years of quiet growth; the original three colonies had grown to number 15 on the eve of the First World War. However, during the war hostility to the German speaking Hutterites forced almost all of them to flee to Canada. One group settled just across the border in Manitoba, while the others moved to Alberta (Evans and Peller 2015b). Today there are some 50,000 Hutterites living in over 490 colonies distributed over four Canadian provinces and six states in the United States (Evans and Peller 2015a, 85). The distribution of these colonies can be viewed on two publicly available digital maps created by the authors. ${ }^{3}$

The two main objectives of this paper are closely allied. The first is to use aerial imagery to make an inventory of selected site characteristics of Hutterite colonies in general. It will be argued that, as the tide of rural settlement continues to recede on the Prairies and Great Plains, so 


\section{Figure 1: Different Perspectives of Hutterite Colonies in the Landscape}

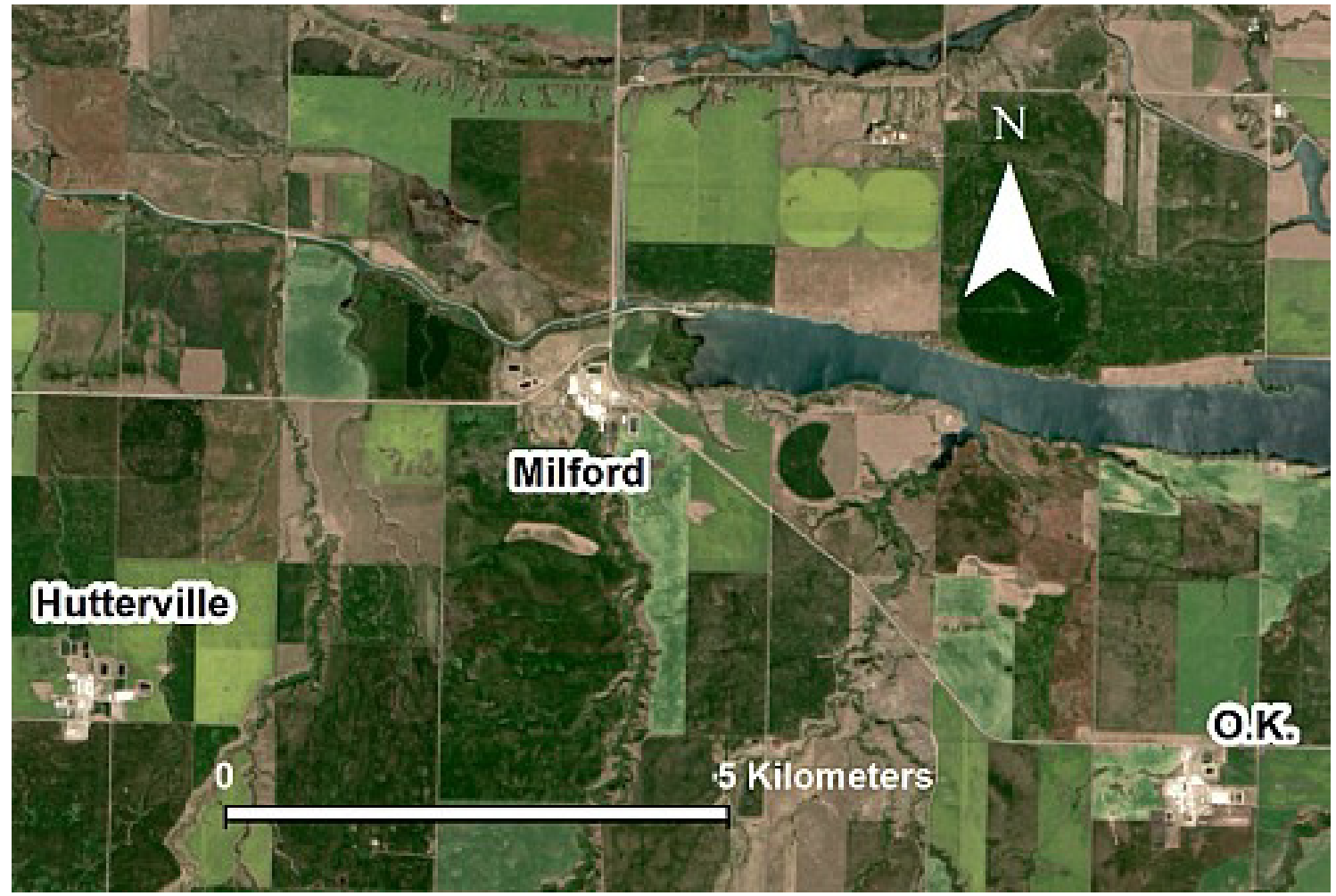

Satellite image of three Hutterite Colonies in the Milk River Reservoir area of Alberta at a scale of 1:100,000. Image: Landsat 8, July 2015, Data available from U.S. Geological Survey.

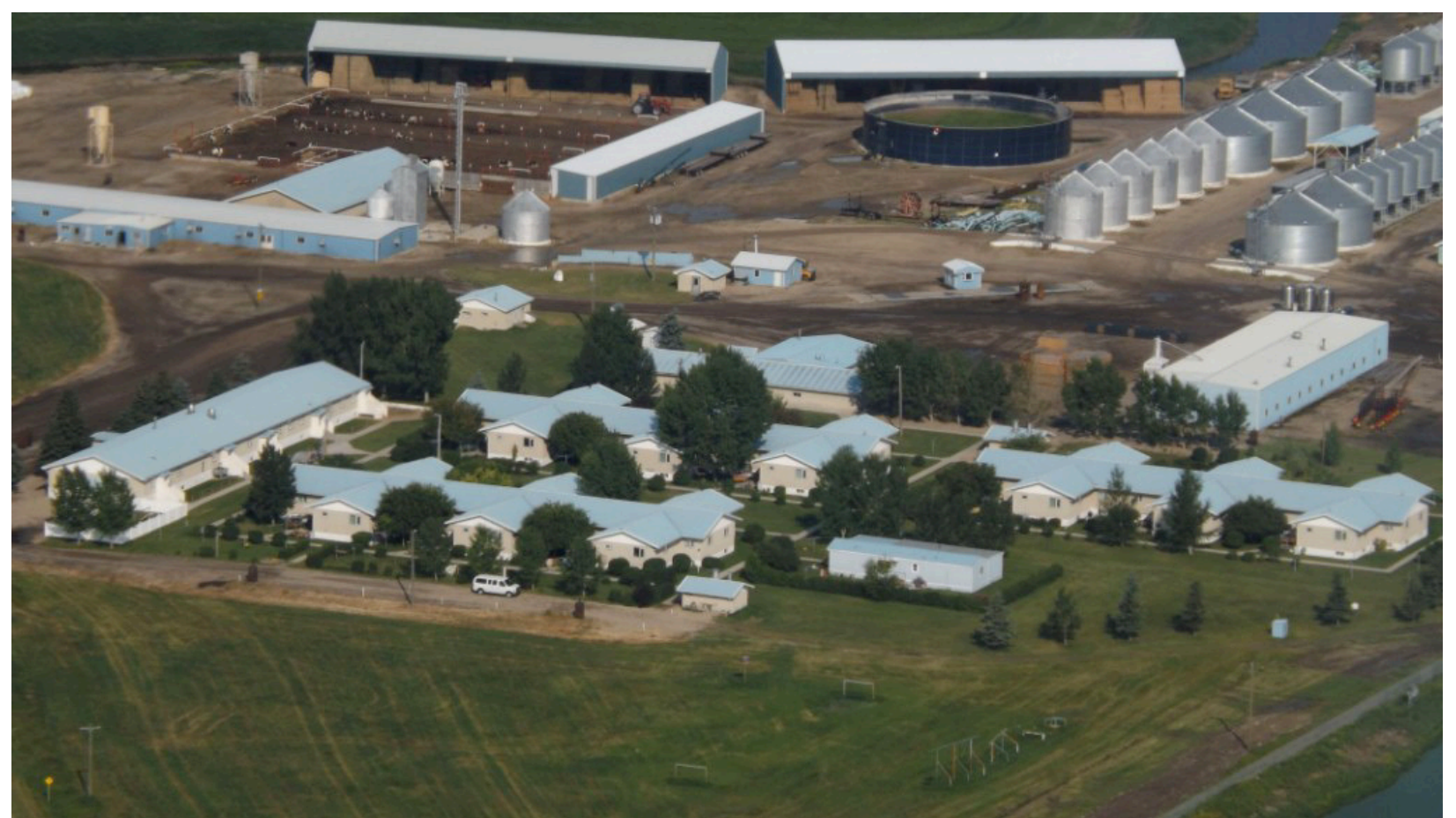

Beiseker Colony, Alberta, Dariusleut, founded 1926. Residential core in the foreground with barns and grain storage behind. Kitchen on left, three 6 unit residences with extensions. Photograph by Simon M. Evans, 2014. 
the growing number of Hutterite colonies constitute an increasingly important element in the cultural landscape. While the diffusion of colonies has been charted with some precision (Evans 1985; Evans 2010), the morphology of these agricultural villages has escaped systematic analysis. If this is the case, then it is incumbent upon us to examine the physical and visual makeup of these colonies in particular. Thus, the second aim of this paper, is to describe the built environment of individual Hutterite colonies and to evaluate contrasts between them over time, space and clan group affiliation. This foundation will provide a basis for comments on the relationship between the form and function of their settlements and the pace and direction of change in Hutterite society in the last part of the paper.

\section{Theme One: The Growing Significance of Hutterite Colonies}

The colony is the essential unit of Hutterite culture. It is within the confines of these communal villages that the brethren live out their lives. Their spiritual life and their daily work are fused together, for it is in sharing their energy and their talents with their brothers and sisters that they do God's will. Daily, in the garden, kitchen, machine shop, or kindergarten, they try to live up to Jesus' injunction to "love one another." During their sojourn in North America the Hutterites have perfected a way of channeling their demographic vigor to insure that it contributes to the maintenance of their way of life, rather than posing a threat. When a colony reaches a threshold size, between 120 and 150 people, it branches in two and establishes a daughter colony (Peters 1976; Janzen and Stanton 2010, 235-240). Both people and assets are carefully divided, half stay at the home place and half move to build up the new place. This cycle of gradual population increase over decades and then colony division, often referred to as "hiving" or "fission", has profound implications for the colony site. As population increases so the existing housing units become over crowded. The remedy may be to add a further multifamily dwelling or to build a number of smaller temporary units, or even to bring in some mobile homes. After the division has occurred there will be surplus space. Large families may be permitted to occupy additional units, while some smaller buildings may be moved to the daughter colony, where this is practical. This process of colony division has led to growth in the number of colonies and diffusion from the original cores of settlement. There were 230 colonies in 1974, 300 a decade later, and 475 recorded by censuses in the US and Canada in 2010/2011 (Hostetler 1974; Evans 1985; Evans and Peller 2015a).

In contrast, a dominant theme in the human geography of the plains has been rural depopulation. Indeed, one view has been to envision a "rewilding" of the grasslands (Popper and Popper 1987; Manning 2011). Certainly, away from urban growth poles and transportation corridors, the tide of rural settlement has continued to recede. ${ }^{4}$ These are counties where the population is stable or declining, with older, less educated folk with lower per capita incomes. Entire regions are more reliant on government transfers, including pensions, and communities live on the defensive, struggling to maintain schools, hospitals and other public services in the 


\section{Figure 2: Close Up of a Colony (Grandview)}

The aerial imagery shows the layout, orientation, and residential core of the colony. The two ground level photographs show two views of housing.

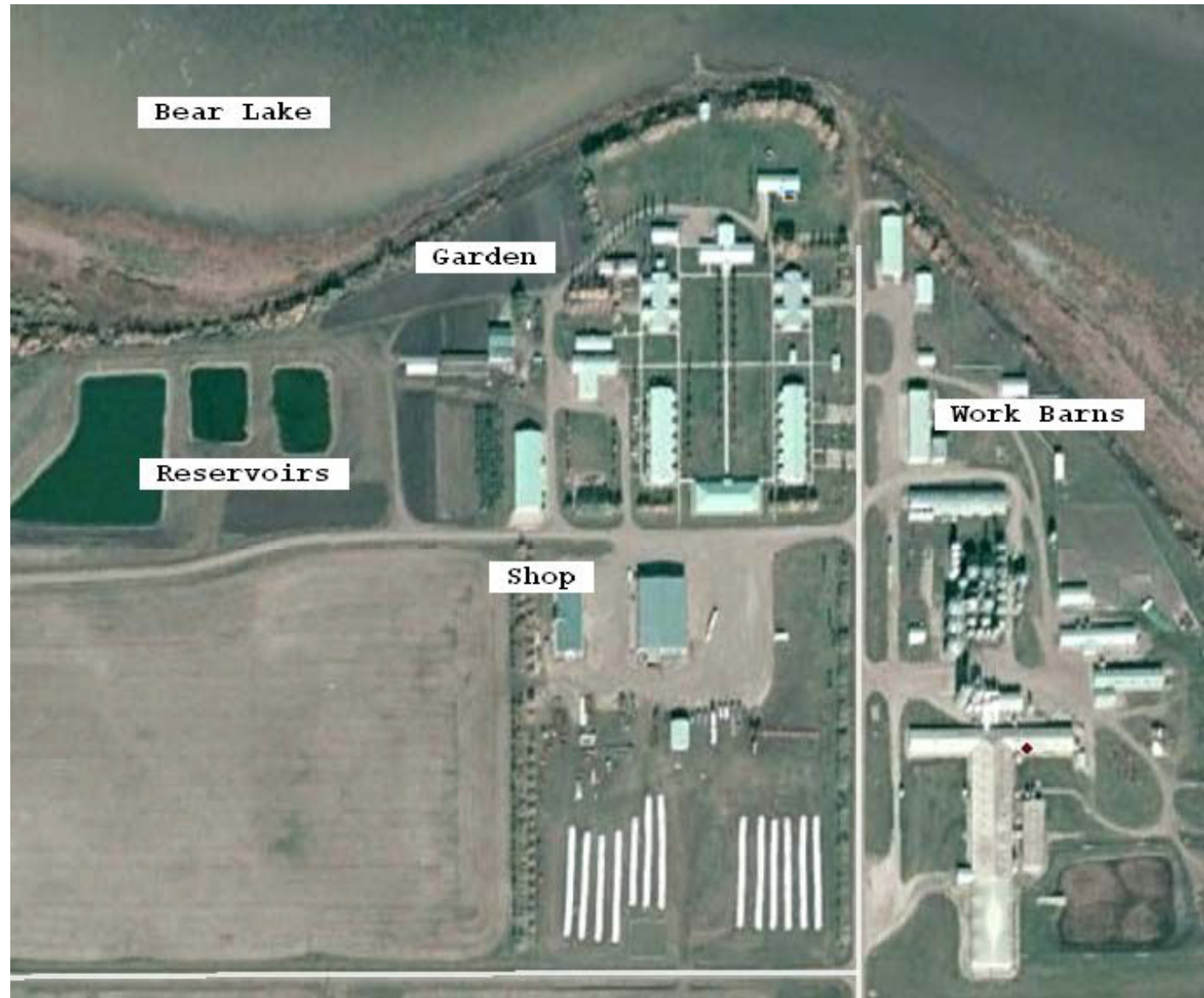

Grandview Colony, Alberta, Dariusleut, founded 1977. Orientation N-S, work related buildings east of range road. Image: Google Earth, 2010, County of Grande Prairie No. 1.

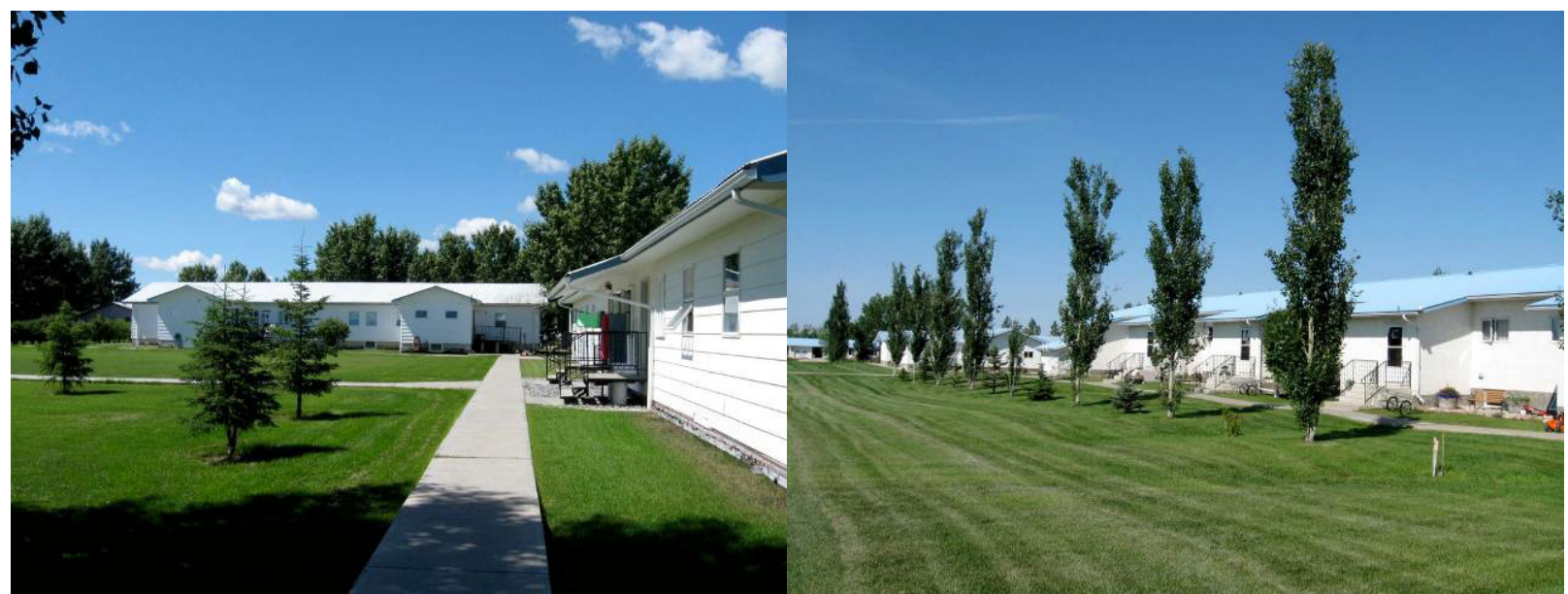

Left: Looking past the kitchen on right to older housing with extensions. Photograph by Simon M. Evans, 2013. Right: Newer row housing, six units, and landscaped court. Photograph by Simon M. Evans, 2013. 
face of population losses and government cut backs (Epp 2005). While some rural towns have emerged as 'winners' with hospitals, high schools and a solid range of retail and service outlets, smaller "minimum convenience" centers have disappeared and the future of many other villages, which are not located on major transport arteries, is in question (Stabler 1992; Stabler and Olfert 2005). To this extent the visual man-made landscape of the Canadian prairies and northern Great Plains has been diminished.

As previously mentioned, during the same period, the number of Hutterite colonies has continued to grow. The time between colony divisions has lengthened as the rate of population increase has slowed, but these farm villages have proved that they can flourish in spite of the challenges faced by the agricultural sector of the economy. A decade hence, another generation of colonies will have been established, bringing the total to more than $700 .^{5}$ This growth will do something to mitigate rural depopulation and to balance the loss of the smallest central places. ${ }^{6}$ Thus, this study can add some precision as to the nature of a feature of growing importance in the cultural landscape of the plains.

\section{Theme Two: Site Characteristics, Diversity, and Change in Hutterite Colonies}

This inquiry focuses on the residential heart of the colony, on the orientation, the plan of the settlement and the nature of the housing. This constitutes an important part of the whole colony footprint, it is easily identified and is amenable to interpretation. The look of Hutterite colonies is described below, and the range of contrasts between colonies over space, time and clan group is explored. Most of the research on the layout of colonies dates back to the 1980s, and there have been significant changes since then. Moreover, previous work was based on a sample of colonies that were used to establish a typical model (Hostetler 1974; Janzen and Stanton 2010; Melland 1985). Presently, using the publicly available sources of imagery described in the Methods section, it is possible to glean a considerable amount of information about almost all colonies in different jurisdictions. This provides an opportunity to move beyond the typical model and demonstrate both the broad uniformity between colonies and the emerging variations in design which are becoming more commonplace.

Any evaluation of the look of Hutterite colonies, and their contribution to the cultural landscape, must take into account not only the diffusion of new colonies, but also the renewal of older parent colonies. The evolution of the colony headquarters site does not cease when division has taken place. The newly established daughter colony will reflect the "state of the art" with respect to new residences, the kitchen and laundry appliances, and the church and school buildings. In contrast, the parent colony will have housing stock which is at least 25-30 years old, and probably 40-50 years old. As soon as the parent colony has recovered from the huge investment they have made in establishing a new colony, leaders will address the problem of inequality between living conditions at the new place and the old. In some cases these plans may only involve modernizing the kitchen or building a new school. Frequently, however, all the accommodation at the parent colony is replaced and the look of the settlement is completely 
transformed. Older colonies, established in the 1920s and 1930s, may well have gone through this process of renewal more than once.

For most of their history in North America the Hutterites have been divided into three clan groups or 'leut': the Lehrerleut, the Dariusleut and the Schmiedeleut. To outsiders the differences between the groups seem slight, but the various traditions and practices of each leut are precious and hallowed by the brethren. There are very few marriages between members of different groups, and there is some degree of geographical separation between them. The Schmiedeleut are located in Manitoba, North and South Dakota and Minnesota, while the Dariusleut and Lehrerleut settled first in Alberta and later diffused into Saskatchewan and Montana, with outliers in British Columbia and Washington State. During the 1990s the Schmiedeleut went through a division between those who were more traditional, and those who were rather more liberal and who were prepared to maintain links with the eastern based Bruderhof, and adopt some of their practices. The leut is now divided into Schmiedeleut One, the more liberal group with 61 colonies, and Schmiedeleut Two with 118 colonies (Janzen and Stanton 2010, 62-72). The cultural differences between the four clan groups-for example their dress, attitudes towards music, and relations with outsiders - are mirrored by contrasts in the layout of their settlements. So important are these differences, that our statistical tables present figures for each leut, and our discussion identifies some of the contrasts between them.

\section{Methods}

The main source of imagery used for the colony classification was Google Earth. It was first necessary to create a layer of georeferenced points for all North American Hutterite colonies (494 colonies at time of writing). This was accomplished by retrieving for each colony its geographic coordinates (latitude/longitude) along with information on its parent colony, date founded and Leut, from the Global Anabaptist Mennonite Encyclopedia Online (Mennonite World Conference Faith and Life Commision 2016) and HB Directory (Hutterian Brethren 2016). A colony shapefile containing this information was created with the ArcGIS software and then converted to a Keyhole Markup Language $(\mathrm{kml})$ file. The resulting $\mathrm{kml}$ file was used in Google Earth to do an audit of the following characteristics of each colony's residential area: geographic orientation, geometric layout, and housing types. For a small number of colonies the Google Earth images were a bit dated, obscured due to cloud or snow cover, or too low a resolution. The ArcGIS Online web map service was used as a secondary imagery source for these cases. With the two imagery sources 487 colonies $(98.6 \%)$ were successfully classified.

The geographic orientation was usually assessed from the direction of the long axis of the residential buildings; however, in cases where buildings were aligned in different directions the long axis of the geometric layout of the whole residential area was used. Where the buildings were equally oriented both N-S and E-W and the layout of the residential area was square, the orientation was categorized as N-S. When there was more than a 5 degree deviation from a N-S or E-W orientation, the orientation was classified as "Other Cardinal". 
Three categories were used to evaluate the geometric layout of the buildings in the residential area. "Rectangular" included rectangular, square, L-shaped and linear layouts. "Innovative" included the following shaped layouts: curved, horseshoe, semi-circle, circle/oval, diamond, triangle, hexagon, fish-bone, and star. When there was no discernible order visible, the layout was classified as "Non-Geometric".

In addition to noting the category of predominant collective housing types, the number of detached single-family dwelling units was also recorded and a ratio of detached to multi-family units was calculated for each colony. The category "Other" was used where the detached singlefamily units exceeded $50 \%$ of the housing on a colony.

It is important to note that the use of remote sensing tools such as Google Earth does not preclude colony visits; in fact, touring colonies and talking to Hutterite leaders is an essential prerequisite for interpreting what is seen on the aerial imagery. Most recently during the summer of 2015, colonies along the Rosebud River and in Vulcan County, Alberta, were visited, while the twelve colonies in the Peace River country were explored in $2012 .^{7}$

\section{Colony Site Characteristics: Statistics}

In the following paragraphs the overall characteristics of Hutterite colony headquarters sites will be introduced. Three tables are used to summarize the geographic orientation, the geometric layout, and the housing types found in the survey.

\section{Geographic Orientation}

Hostetler's (1974) account of colony organization is an outgrowth of his analysis of the Hutterite worldview. He observes: "The Hutterite world view leads to the creation of an earthly environment that is orderly spatially, temporally, socially, and symbolically" (153). Because they are sojourners and have been forced to move frequently, the Brethren create their own uniform physical environment, in which everyone knows their place and in which socialization of the young can proceed uninterrupted. With respect to orientation, Hostetler quotes a preacher who explained why the long houses of the headquarters sites run due north and south. He said: "They are all squared with the compass. You don't walk crooked on the earth, you walk straight, this is how buildings should be, straight with the compass and not askew" (155)

Our inventory found that three-quarters of all the colonies were indeed orientated north to south [Table 1]. Among the Lehrerleut this figure approaches $100 \%$. Interestingly, quite a number of the older colonies are laid out just a few degrees off north. Today's township roads, laid out more recently and with more sophisticated technology, bring this discrepancy to light. ${ }^{8} \mathrm{~A}$ growing number of Dariusleut colonies are aligned East-West. Many of the colonies aligned between the major cardinal points of the compass reflect the unique characteristics of their locations; some are aligned along riverbanks, while others nestle within the curves of meanders, like Bloomfield Colony, ${ }^{9}$ Manitoba. 


\section{Table 1: Geographic Orientation}

\begin{tabular}{|ll|c|c|c|c|}
\hline Orientation & & All Colonies & Dariusleut & Lehrerleut & Schmiedeleut* $^{*}$ \\
\hline North-south & $\mathrm{n}$ & 370 & 116 & 139 & 115 \\
& $\%$ & 76 & 73 & 98 & 62 \\
\hline East-west & $\mathrm{n}$ & 72 & 25 & 1 & 46 \\
& $\%$ & 15 & 16 & 0.7 & 25 \\
\hline Other cardinal & $\mathrm{n}$ & 30 & 12 & 2 & 16 \\
& $\%$ & 6 & 7 & 1 & 7 \\
\hline No obvious & $\mathrm{n}$ & 15 & 6 & 0 & 9 \\
orientation & $\%$ & 3 & 4 & 0 & 5 \\
\hline Totals & $\mathrm{n}$ & 487 & 159 & 142 & 186 \\
\hline
\end{tabular}

*There were no obvious differences between $\mathrm{S}_{1}$ and $\mathrm{S}_{2}$ colonies - partly because so many colonies were established before the split—so all Schmiedeleut are amalgamated in this and the other tables.

\section{Geometric Layout}

The majority of Hutterite colonies were laid out in a rectangular grid conformation [Table 2]. However, the details of this geometry vary between the clan groups. The Lehrerleut colonies display long narrow rectangular plans, defined by their multi-family row housing. Their common buildings are located in a parallel line between the residences. The Dariusleut colonies tend to have a shorter primary axis, and in many cases the kitchen and church may be built at right angles across the top and bottom of the rectangle to enclose it. The Schmeideleut colonies tend to be square, primarily because they have opted for smaller residential housing. This group leads the way with respect to innovative new designs for their colonies, with $18 \%$ of their colonies breaking new ground. There are eleven colonies that are harder to interpret; the buildings appear to be grouped around the kitchen in a random fashion. While some of these sites have become more complex over time, others chose a less structured form for their living space from the beginning.

\section{Table 2: Geometric Layout}

\begin{tabular}{|ll|c|c|c|c|}
\hline Layout & & All Colonies & Dariusleut & Lehrerleut & Schmiedeleut \\
\hline Rectangular & $\mathrm{N}$ & 428 & 142 & 139 & 147 \\
& $\%$ & 88 & 89 & 98 & 79 \\
\hline Innovative & $\mathrm{N}$ & 48 & 12 & 3 & 33 \\
& $\%$ & 10 & 8 & 2 & 18 \\
\hline \multirow{2}{*}{ Non-Geometric } & $\mathrm{N}$ & 11 & 5 & 0 & 6 \\
& $\%$ & 2 & 3 & 0 & 3 \\
\hline Totals & $\mathrm{N}$ & 487 & 159 & 142 & 186 \\
\hline
\end{tabular}




\section{House Types}

Our inventory of sites and house types on Hutterite colonies comes at the end of a fortyyear period of change and experimentation. In their recent book Katz and Lehr $(2012,190)$ comment:

...only a few decades ago they used to draw water from wells in the yards, bathrooms were outside the house, there were no kitchens in the houses... and the houses in general were much smaller. A house in James Valley Colony (Manitoba) that today is occupied by a family of four might have housed up to 17 people only 40 years ago. ${ }^{10}$

Ryan (1977, 29) and Becker (1989, Part 1) describe the transition in Manitoba from the first generation of frame multi-storey houses to smaller more modern housing, and the widespread adoption of duplexes among the Schmiedeleut during the 1970s and 1980s. The figures in Table 3 suggest that this process has, for the most part, run its course. Today most colonies in Manitoba and the Dakotas have a nucleus of duplexes and some additional row housing.

\section{Table 3: House Types}

\begin{tabular}{|ll|c|c|c|c|}
\hline Housing & & All Colonies & Dariusleut & Lehrerleut & Schmiedeleut \\
\hline Row & $\mathrm{n}$ & 231 & 77 & 127 & 27 \\
& $\%$ & 47 & 48 & 89 & 14 \\
\hline Ls* & $\mathrm{n}$ & 28 & 23 & 5 & 0 \\
& $\%$ & 6 & 15 & 3 & 0 \\
\hline Mixed Row \& & $\mathrm{n}$ & 57 & 46 & 9 & 2 \\
Ls* & $\%$ & 12 & 29 & 6 & 1 \\
\hline Duplex & $\mathrm{n}$ & 29 & 0 & 1 & 28 \\
& $\%$ & 6 & 0 & 1 & 15 \\
\hline Mixed Row \& & $\mathrm{n}$ & 123 & 1 & 0 & 122 \\
Duplex & $\%$ & 25 & 1 & 0 & 66 \\
\hline Other (Trailers & $\mathrm{n}$ & 19 & 12 & 0 & 7 \\
and bungalows) & $\%$ & 4 & 8 & 0 & 4 \\
\hline Totals & $\mathrm{n}$ & 487 & 159 & 142 & 186 \\
\hline
\end{tabular}

* Ls $=$ Houses with extensions to house bathrooms.

Melland $(1985,290)$ described the incremental process by which modernization was achieved on Lehrerleut and Dariusleut colonies. The first stage involved building extensions onto existing multi-family houses. This new space was used for a bathroom, and a partial basement was excavated for the water heater and furnace. These 'Brant style' houses, providing homes for four or six families, spread widely during the 1980s. However, it was not long before new daughter colonies began to appear with long low row houses in which six to eight family units were aligned side by side. Typically, these dwellings had full basements. They were thought to be 


\section{Figure 3: Change along the Rosebud River (Sandhills)}

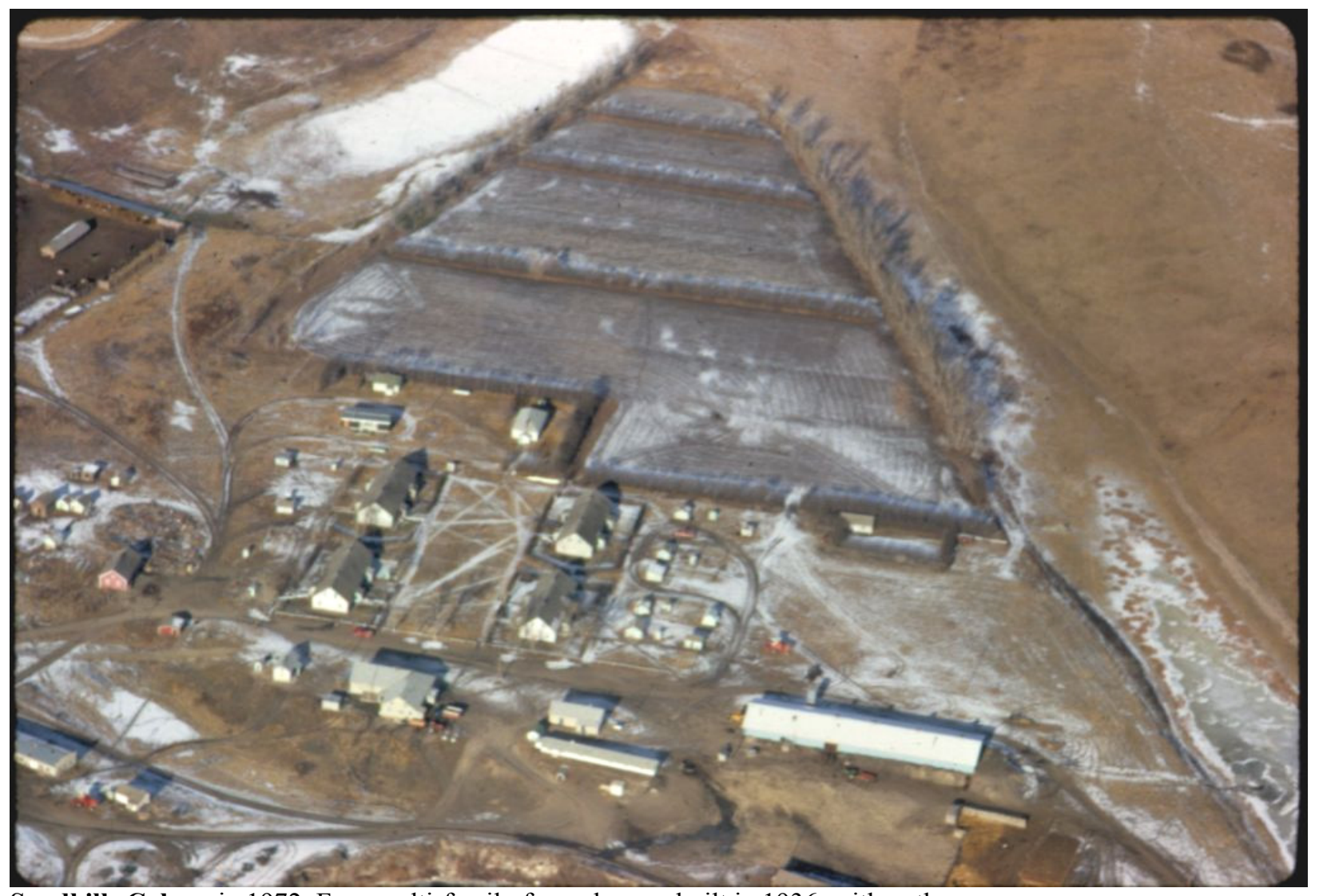

Sandhills Colony in 1972. Four multi-family frame houses built in 1936, with outhouses.

Photograph by Simon M. Evans.

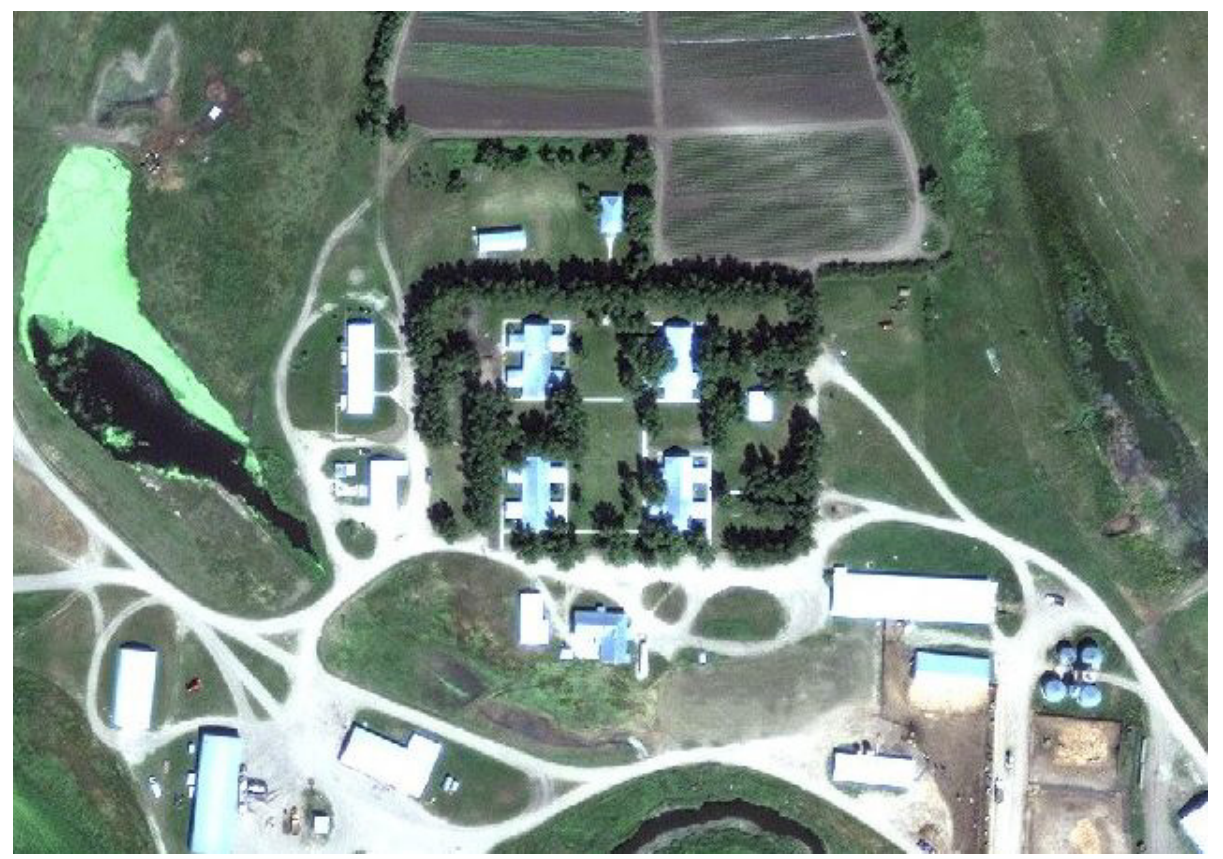

Sandhills Colony in 2011. Four "Brant style" buildings with extensions (no outhouses). Image: Google Earth, 2011, DigitalGlobe. 
cheaper and easier to construct, and had the aesthetic appeal of simple clean lines. The Lehrerleut have completed transition to this design, and only nine colonies still have some residences with extensions. As is so often the case, the Dariusleut display more diversity. While many colonies have adopted row housing, many others have a mix of the older design and the new. Indeed, there are some colonies that have recently completed major rebuilding projects that have elected to stay with the familiar house type. It must be said, that although all row houses present a uniform 'footprint' from the air, there is a considerable range of styles on the ground. In most cases the main floor is reached by ascending steps either outside or in the hallway. Some colonies have walkout basements with lots of windows, while others are only used for storage and perhaps a bedroom for boys.

\section{Single Family Dwellings}

One of the unexpected findings of this research was the prevalence of single-family dwellings on several of the colonies of this communal group. The average number of residential units on all colonies was $22 .{ }^{11}$ Among the Schmiedeleut, $16 \%$ of their units were designed for single families, while the corresponding figure on Dariusleut colonies was $12 \%$. There were very few single-family units on Lehrerleut colonies $(0.3 \%)$.

The averages mask great differences between colonies within each clan group. There are many colonies without any single-family dwellings and others on which old farm houses, trailers, and bungalows make up more than half of the available accommodation. This is particularly true of the Schmiedeleut as a whole, and of colonies in the Dakotas in particular. For example, Grassland, in South Dakota, is a S2 colony founded in 1990; it boasts eight trailers as well as two duplexes and four multi-family row houses.

Of course, the use of mobile homes and existing houses during the construction phase of establishing a new colony is a well established practice. The image of Vauxhall Farms, a Dariusleut colony in Alberta, illustrates this. A neat row of mobile homes provide temporary accommodation while the full complement of multi-family houses are being constructed to the west. In contrast, on the group of Dariusleut colonies surrounding Lewistown, Montana, singlefamily units make up a large proportion of the available living space and seem to be the preferred option. The significance of single-family housing will be considered below.

This preliminary description has presented statistics on some observed characteristics of a large sample of images of Hutterite colonies. The figures confirm what the literature has made abundantly clear, that there are marked differences between the clan groups. The following paragraphs examine in more detail these dissimilar attributes, starting with the Lehrerleut.

\section{Lehrerleut Colony Characteristics}

The Lehrerleut exhibit a remarkable degree of uniformity in the way they organize their living space. Whether it is an old colony or a new one, located in Alberta, Saskatchewan or Montana, from the air Lehrerleut colonies look almost identical. 


\section{Figure 4: A Typical Lehrerleut Colony (Brant)}

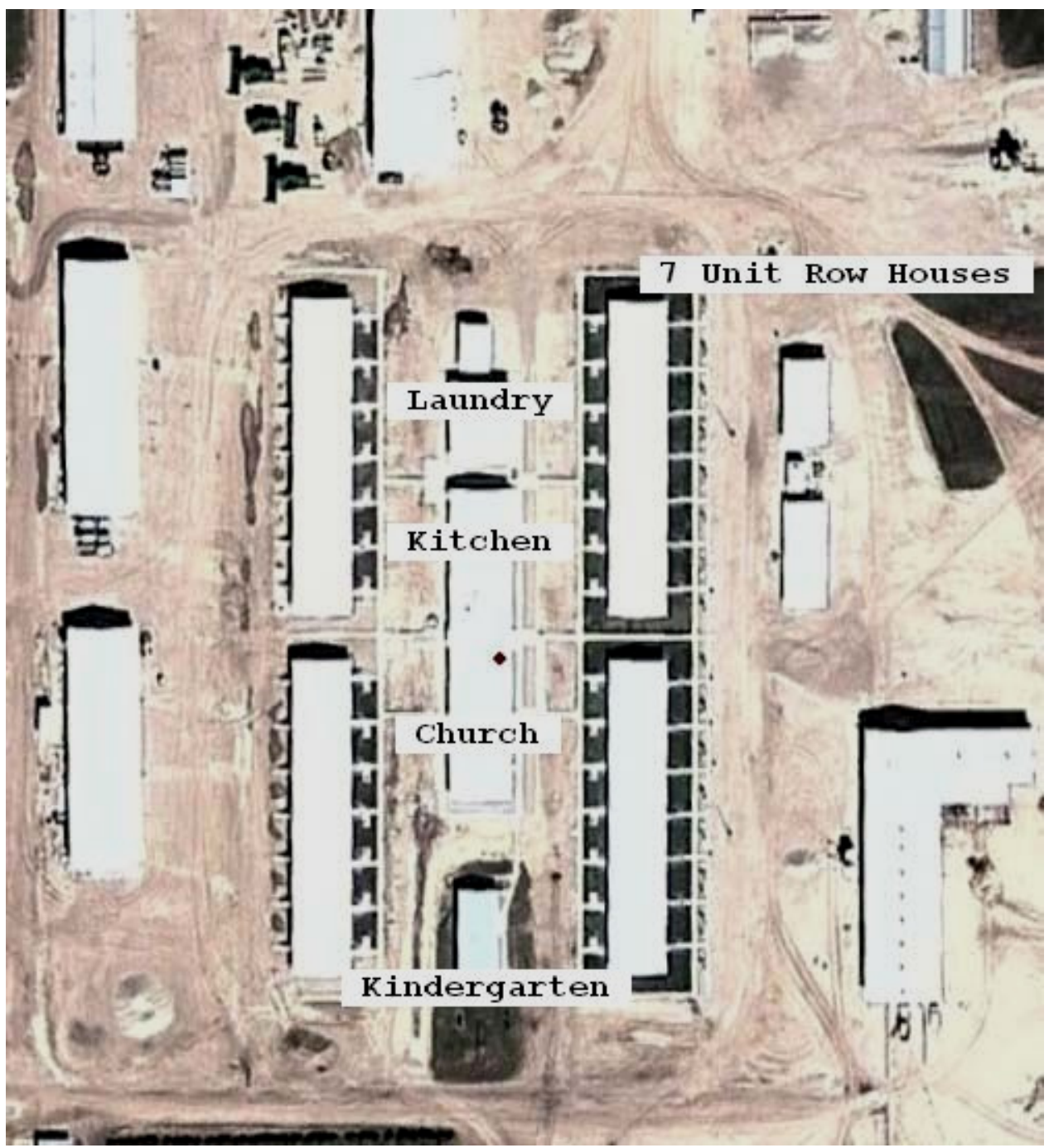

Brant Colony, Alberta, Lehrerleut, founded 1968. Orientation N-S, the long 7 unit residences give rise to a typical rectangular plan. Common buildings in the middle. Image: Google Earth, 2012, DigitalGlobe.

With very few exceptions, colonies are aligned North to South. Typically, a rectangular plan is framed by four row houses, each divided into seven or eight units. In the middle stands the kitchen complex, which in many of the more recently remodeled colonies, contains a church. Two smaller buildings in this central row of communal buildings house the laundry and the kindergarten. Milford Colony in Montana, originally founded in 1947, has been rebuilt to exemplify this model. The layout can be compared with Haven Colony in Saskatchewan (1967), and with the recently built colony of Armada in Alberta (2002).

Lehrerleut colonies are meticulously neat and rather austere looking. Landscaping is usually limited to functional shelterbelts and to tiny patches of grass around the houses. Much of the open space between the residences and the work buildings is covered with gravel or left as 


\section{Figure 5: Lehrerleut Colonies (Milford, Haven, and Butte)}

Almost all Lehrerleut Colonies look the same, regardless of the time of establishment or location.
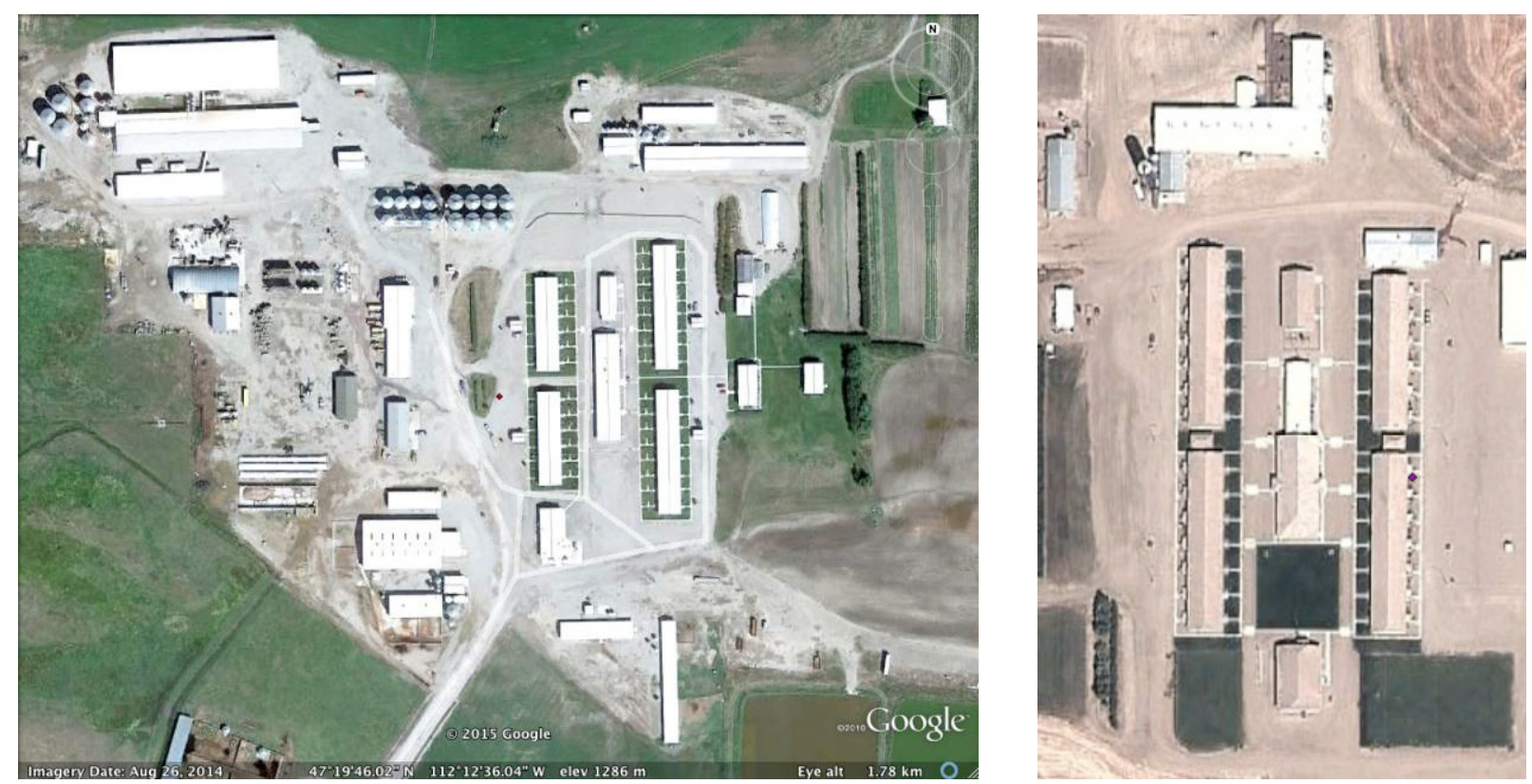

Left: Milford, Montana, founded 1947. Image: Google Earth, 2014. Right: Haven, Saskatchewan, founded 1967. Image: Google Earth, 2012, DigitalGlobe.

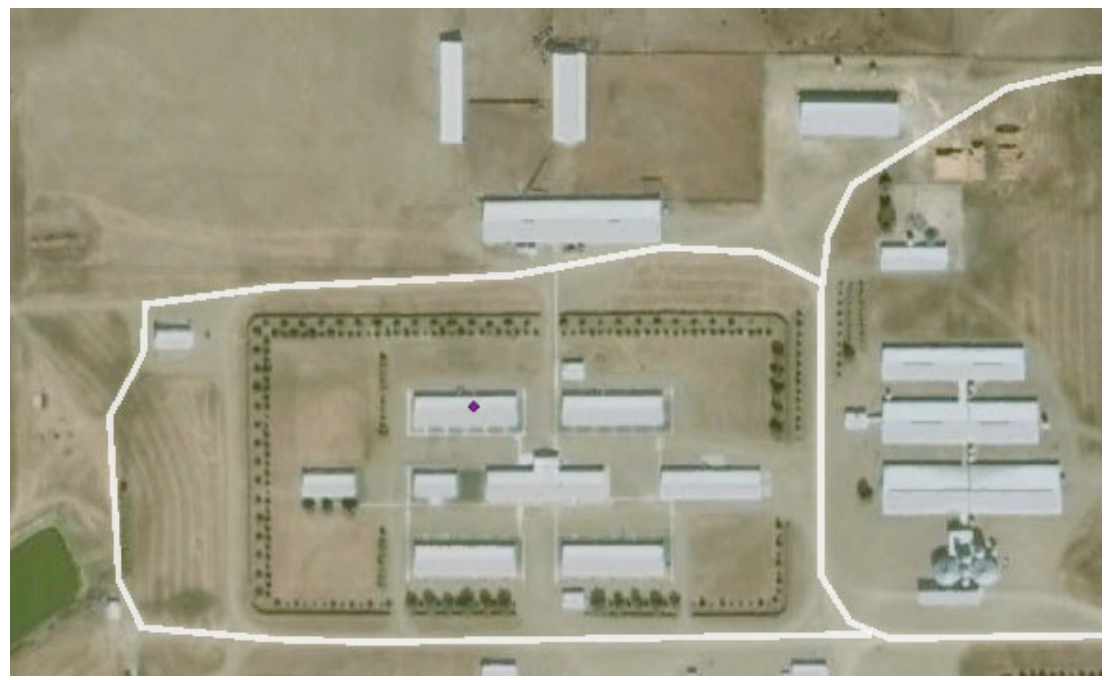

Butte, Saskatchewan, founded 1991. The only Lehrerleut colony orientated east to west. Notice the elaborate windbreaks. Image: Google Earth, 2006, DigitalGlobe.

bare earth. At first glance this presents a rather unattractive and 'cold' impression, but it has some pragmatic advantages. Gravel between the houses drains well, requires a minimum of maintenance, allows occasional access to vehicles, and encourages the use of concrete walkways, which are cleared of snow during the winter. Even among the Lehrerleut there are slight differences in ambiance between one colony and another. Some have rather more green space, mature trees and even flower gardens, while others are bereft of any softening touches. These 
differences reflect both the age of the colony and the attitudes of the leadership.

The aerial imagery of these colonies freeze the buildings at one moment in time. In reality these Lehrerleut colonies — indeed most Hutterite colonies — are undergoing almost constant change. Among a handful of Alberta colonies visited during 2015: Riverbend is in the process of replacing their kitchen complex with a sleek new building which will include a church; Brant has just completed a multi-classroom state of the art school building with a large attached gymnasium; while neighbouring Wild Rose Colony has almost completed the long process of remodeling all its residences. Everywhere infrastructure is being updated and construction is underway. This means work for colony plumbers, electricians, carpenters, sheet metal fabricators and machine shops. Almost all the physical construction work on a colony is done "in house". Only where bylaws and building codes are involved do colonies enlist the help of outside specialists to develop plans and guide them through the bureaucratic hoops. Nor should the plain outward appearance of colonies be allowed to tell the whole story. Many contemporary colonies enjoy a level of comfort — not to say luxury — quite foreign to many householders in the suburbs of major cities. Residences and common buildings have under-floor hot water heating pumped from a central boiler house. Built in cupboards and linen closets are designed to meet the needs of women, and a kitchen nook equipped with a refrigerator and microwave allows the preparation of snacks between meals in the communal dining-room. Family units contain two bathrooms and toilets are fitted with elaborate bidet systems.

\section{Dariusleut Colony Characteristics}

There is much more diversity in the layout and conformation of Dariusleut colonies. But it is important to remember - as some of these idiosyncratic characteristics are described - that all colonies have much in common, and that differences are merely variations on a familiar theme rather than wholesale departures from tradition. A Hutterite family transported from Rock Lake Colony, depicted in a map by Hostetler as it was in 1965, would have no difficulty finding their bearings and feeling at home in a modern colony like Arrowwood, Alberta or Big Sky, Montana $(1974,156)$. Most Dariusleut colonies are laid out to precise geometric patterns and their multi-family housing units display many of the characteristics already described. With this important proviso, some of the ways the Dariusleut have tweaked traditional aspects of their living space will be examined.

Three-quarters of the Dariusleut colonies in Alberta are laid out with a North to South axis. But this of course means that one quarter of the colonies are aligned differently. Thirteen colonies are orientated East-West. In some cases this may reflect a conscious effort to benefit from passive solar energy. Thirty years ago, on a visit to the newly established Berry Creek colony, the boss explained that they had decided to build row housing and to align it East-West. He boasted that they were already benefiting from lower heating costs. Eight other colonies are aligned between the cardinal points of the compass, like Beiseker, Alberta. In addition, a handful of colonies have evolved with no obvious plan or orientation. 


\section{Figure 6: A Typical Dariusleut Colony (Swift Current)}

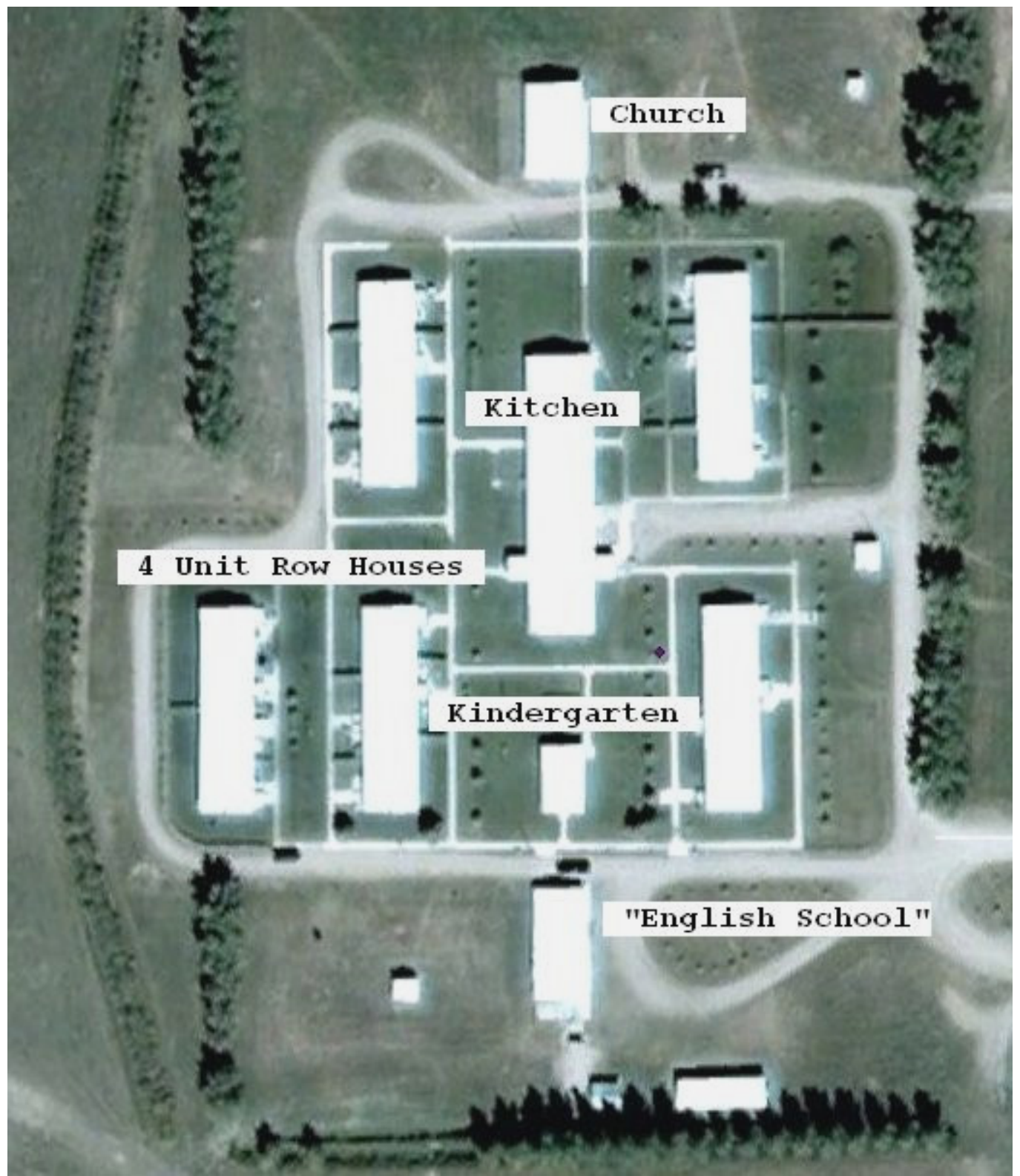

Swift Current Colony, Saskatchewan, Dariusleut, founded 1978. N-S orientation; the adoption of 4 unit row housing means the plan is roughly square. Image: Google Earth, 2005, DigitalGlobe.

The majority of Dariusleut plans are geometric and rectangular, and yet there is a marked difference from Lehrerleut layouts. In many cases the North-South axis is shorter and is matched by an East-West dimension to give a square shape rather than an obvious rectangle. Unlike the Lehrerleut, the Dariusleut have opted to build freestanding churches set apart from the other communal buildings. Thus, in a newer colony like Arrowood, Alberta, the residences are flanked to the east by the kitchen and to the west by the imposing church building. Several colonies have modified the rigid rectangular layout by angling some residences to form an open diamond shape, while a few colonies have experimented with more radical plans. Red Willow aligned its 


\section{Figure 7: Four Dariusleut Colonies with Different Layouts (Red Willow, Bell Plaine, Ayers Ranch, East Cardston)}
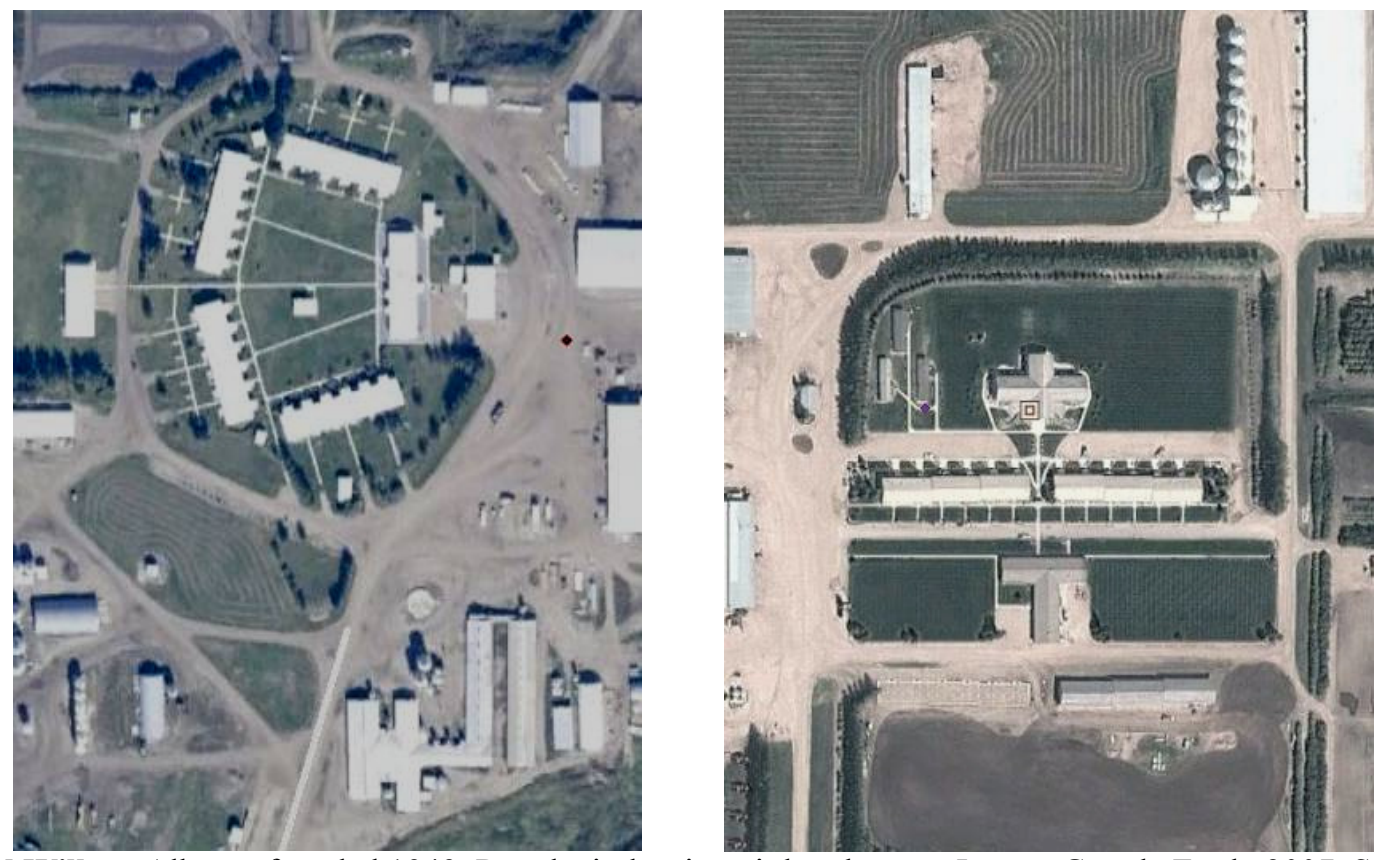

Left: Red Willow, Alberta, founded 1949. Rough circle, six unit longhouses. Image: Google Earth, 2007, Stettler Co. Right- Bell Plaine, Saskatchewan, founded 1990. Linear, church to north, kitchen to south. Image: Google Earth, 2016, DigitalGlobe.
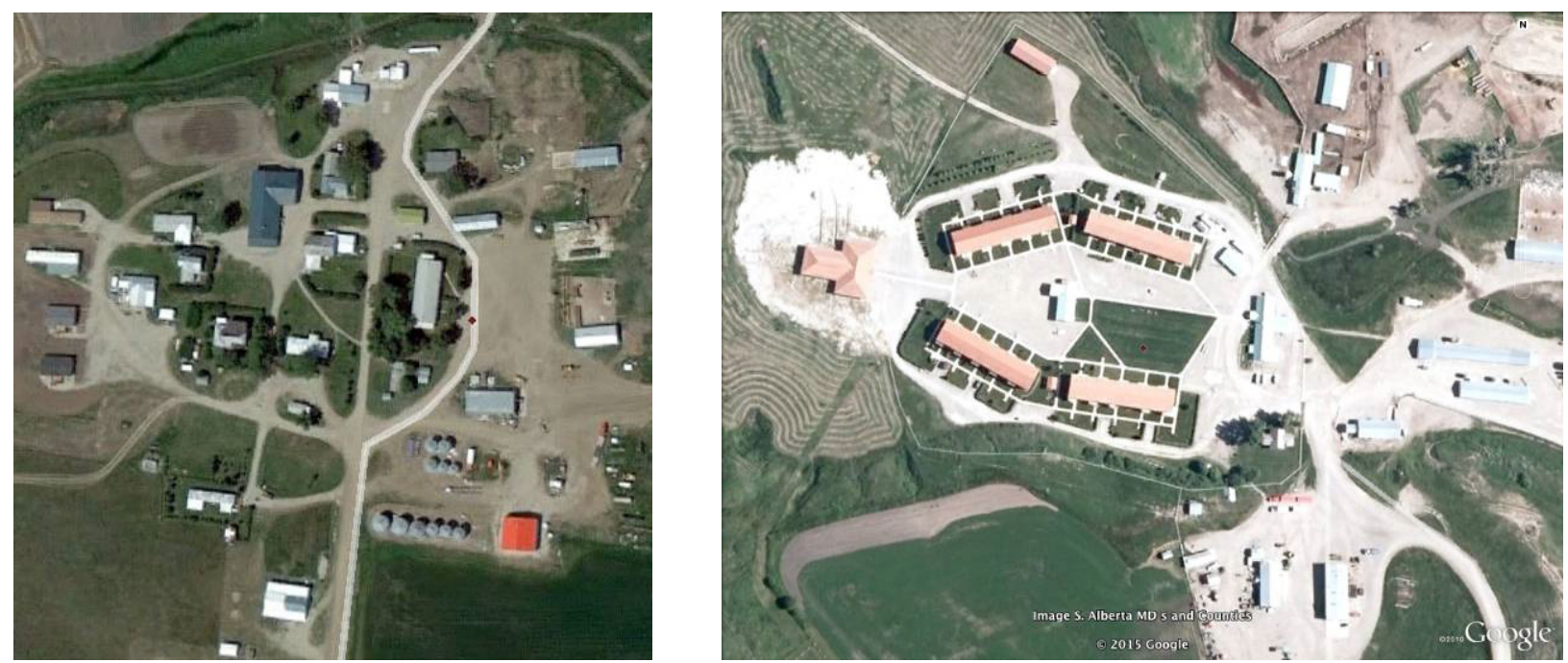

Left: Ayers Ranch, Montana, founded 1945. Unplanned, houses and trailers. Image: Google Earth, 2013. Right: East Cardston, Alberta, founded 1918. Arc layout, still developing. Image: Google Earth, 2011, S. Alberta MDs \& counties.

four residential units to form a loose circle focused on the kitchen/dining room complex.

Vauxhall Farms, established in 2008, has built three residences in an arc and it will be interesting to see how this plan develops. East Cardston too has rebuilt its housing on an oval plan. Finally, there are a handful of colonies that do not have a geometric plan. Thompson and Ribstone are representative of this class. In both cases there is a variety of non-uniform residential buildings 


\section{Figure 8: Standoff Colony, Alberta}

\section{Standoff Colony has a long history. Several of the structures built in 1918 can be identified, although altered and adapted over the years.}

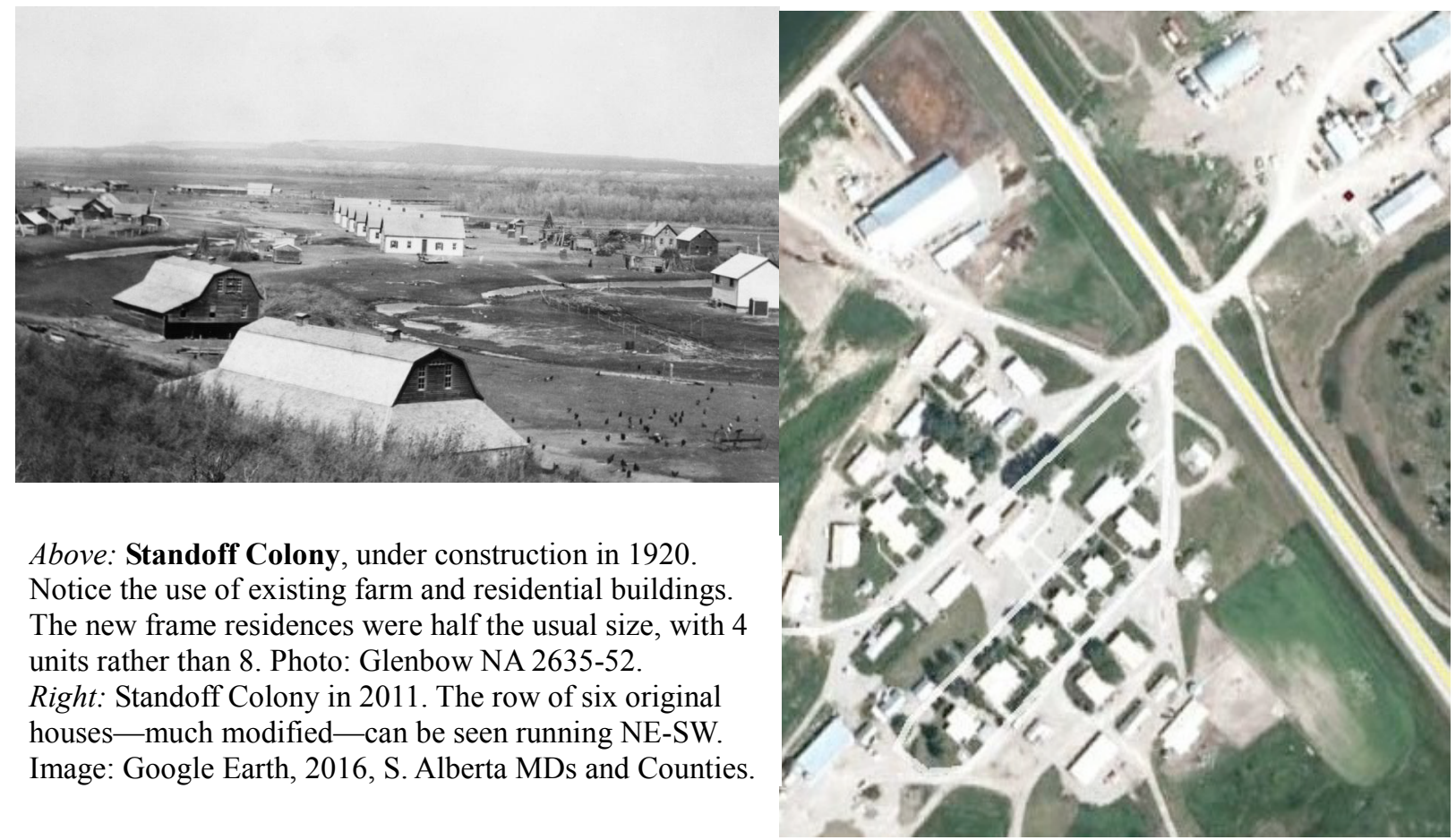

apparently situated at random. Pincher Creek is also a complex site to analyze, but it does incorporate some traditional multi-family houses at its core.

Multi-family row houses are the most common housing type adopted by the Dariusleut. But, unlike the Lehrerleut, they have retained many more rather older homes with extensions. The Dariusleut have been rather less eager to rebuild and modernize their housing on a wholesale basis. They have preferred a more piecemeal approach, so that the older and the new often stand side by side. There are a number of Alberta Dariusleut colonies that display anomalous housing characteristics. Standoff is an interesting example. Established in 1918, the original frame housing units were half the size of those built elsewhere. They provided homes for 4 families rather than 8 . Through the decades since, the colony has transported some buildings to the colony and built some non-traditional houses. The present site is complex. Thompson and Pincher Creek share similar characteristics.

Dariusleut colonies in Montana present a marked contrast to those elsewhere. For the first time in this inquiry there is a group of colonies which display consistent departures from the norms. Eight of the fifteen Dariusleut colonies in the state have no obvious plan. An example would be the sprawling King Ranch which has 8 houses - some clearly multi-family - and 5 trailers. The site is masked with trees and it is hard to distinguish the communal kitchen. At 
Ayers Ranch too there are 8 or 9 houses, as well as a row house with four units and two custom built single-family units. They are neatly arranged but without a geometric plan. The eight colonies, which share this lack of concern for rigid planning, are all related. The original colonies came directly from South Dakota rather than from Alberta. In contrast, Deerfield Colony (1947) and the colonies derived from it display a range of more traditional plans and housing types. Deerfield itself has a somewhat loose plan but has four multi-family row houses. Its daughter colony North Harlem (1963) has a neat geometric plan comparable to many Dariusleut colonies in Alberta. Gildford (1974) and Loring (1981) are also carefully laid out and feature row housing. These colonies are located in the Havre region of northern Montana.

\section{Schmiedeleut Colony Characteristics}

The Schmiedeleut are often described as the most liberal of the Hutterite clan groups (Janzen and Stanton 2010, 62). Certainly, their colonies have a rather different feel to them. They are smaller and more compact. This is partly due to the denser settlement pattern in Manitoba, but it is also explained by crucial collective decisions made during the 1960s and 1970s.

\section{Figure 9: A Typical Schmiedeleut Colony (Brentwood)}

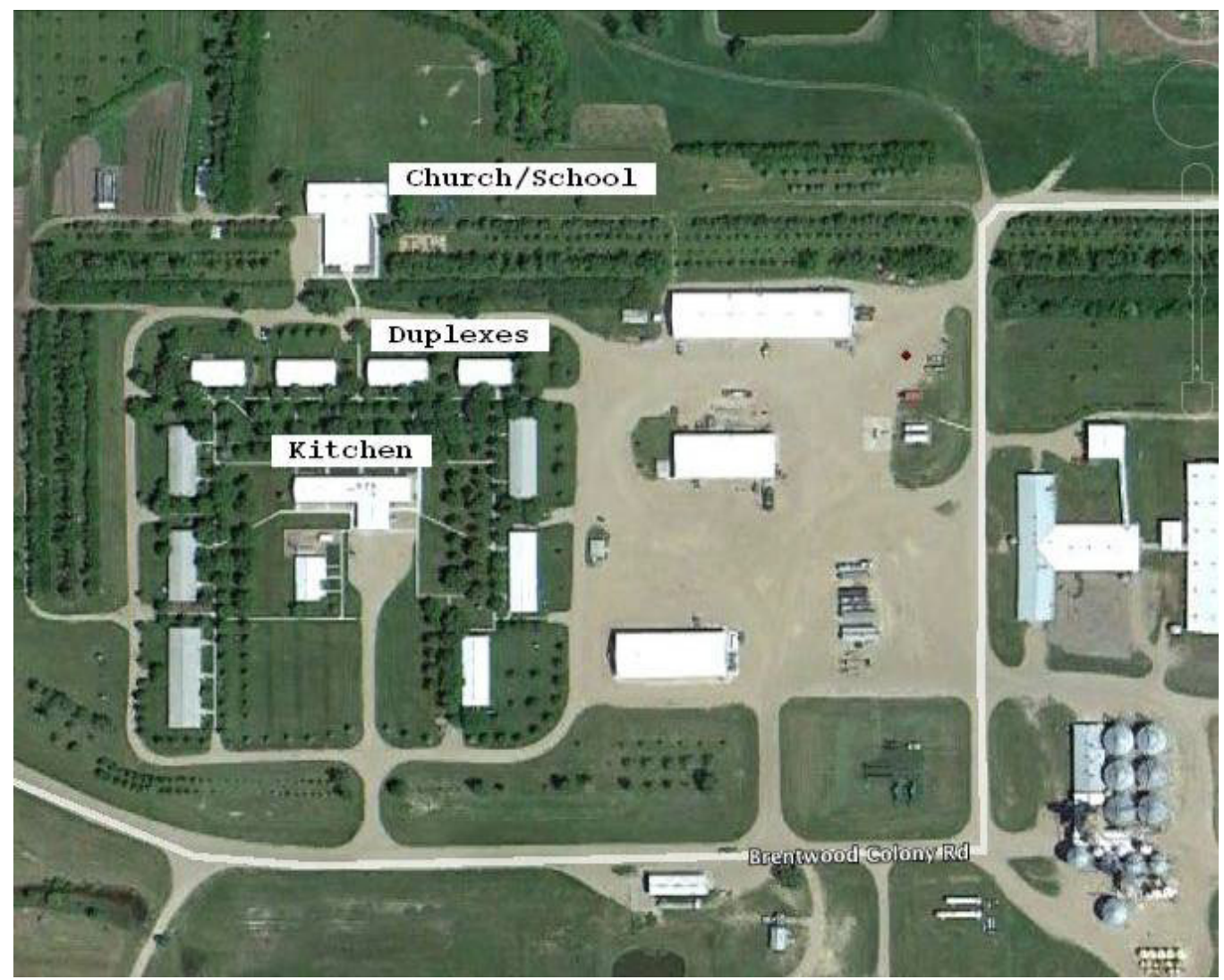

Brentwood Colony, South Dakota, Schmiedeleut 1, founded 1987. Duplexes in a square around the kitchen. Church/school complex a more recent addition. Image: Google Earth, 2014. 


\section{Figure 10: A Site That Has Become More Complex as Buildings Have Been Added (Maxwell)}

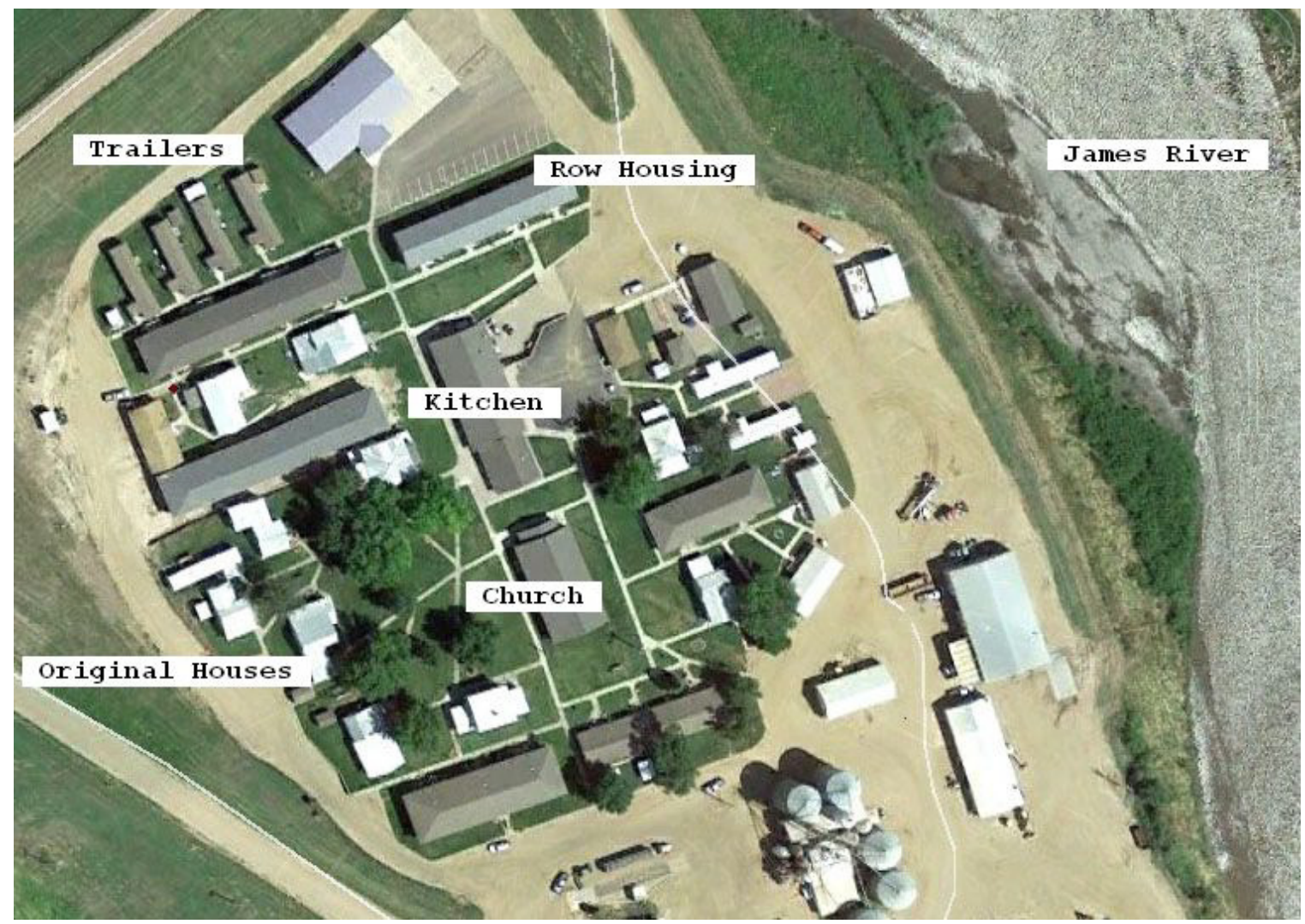

Maxwell Colony, South Dakota, Schmiedeleut 2, founded 1949. Orientated along the banks of the James River, this colony shows the effects of adaptation and agglomeration. There are 10 original houses, along with modern row houses, duplexes, and trailers. The site is carefully laid out if rather dense. Image: Google Earth, 2015.

A tide of anti-German sentiment drove the Hutterites from South Dakota in 1918. Across the border in Manitoba, the Schmiedeleut built colonies which mirrored the homes that they had been forced to abandoned. Long two-storey wood-frame houses were constructed, each providing space for eight families. Forty years later these structures had to be replaced, and the sensibilities of the Hutterites had changed. They were less threatened by the host society and had enjoyed decades of material prosperity. The Brethren were ready to consider more modern homes with rather more space for each family and with inside bathrooms. The post-war housing boom influenced those responsible for planning daughter colonies and renovating older ones. They saw the houses being built in "the world" outside the colonies, and learned from designs promoted in Farm Life Manitoba and other journals (Becker 1989, 137). Some colonies abandoned the longhouse and experimented with semi-detached houses, single-family bungalows, and three or four unit row houses. Other colonies were quick to follow suit. Over the years the duplex emerged as the most ubiquitous choice, although many colonies have a mixture of duplexes and row housing (Ryan 1977, 24). 
The adoption of these smaller houses had far reaching implications for the layout of colonies, for the units could be arranged in a variety of ways. The majority of Schmiedeleut colonies are laid out in a simple geometric grid. But these sites tend to be square rather than rectangular, as is so often the case among the Dariusleut and Lehrerleut. Typically a ring road demarcates a square and houses are spread around the edges backing onto the road, while the kitchen commands the centre. Brentwood, South Dakota, and Aspernam, Manitoba, are good examples. Each unit has access to the road and a parking space, which suggests that the Schmiedeleut have significantly increased the number of vehicles on the colony (Katz and Lehr 2012, 190).

Maxwell colony, on the banks of the James River in South Dakota, was established in 1949, and provides an example of a rather complex site where several eras have contributed to the present plan. Originally, several existing buildings were adapted for colony use and others were acquired and transported to the site. Some ten of these houses are still in use, but most of the population is housed in modern row housing laid out around and between the older structures. Most recently, eight trailers have been added to cope with the burgeoning population.

In other cases the clean lines of the original colony plan have been confused and made more complex by the addition of more and more residential buildings. Typical would be the irregular pattern of Barrickman or Riverdale colonies in Manitoba, or Tschetter, Glendale and Platte colonies in South Dakota. However, it is important to note that there is a contrast between these neat, but rather overdeveloped colonies, and those non-geometric and rather chaotic plans described earlier among the Dariusleut.

There are a number of Schmiedeleut colonies, especially in Manitoba, which are laid out in a boldly innovative fashion. Perhaps the most striking of these is Starlight Colony. This colony's plan was conceived as a circular site in which the residences would encircle the kitchen and the church. One justification for the design was that all the residences would be the same distance from the dining room, thus enhancing the principle of equality. Becker was carrying out research at James Valley Colony when the plan for this radical design was being implemented. She was critical of the plan because of its monumental scale and the exposure of the site. Initially, the daughter colony had only 65 people and the circle of residences was far from complete. Twenty-six years later, all the homes have been completed and trees and shrubs have done much to mellow the site (Becker 1989, 137-138). Four other colonies have followed Starlight's lead: Green Acres, Norquay, Prairie Blossom and Blue Clay. In addition, it seems probable that Northern Breeze and Oak River will evolve from half-circles to complete circles when they are fully developed. Thus, nearly a quarter of the Schmiedeleut colonies established in Manitoba since 1990 have chosen circular plans. Interestingly, this innovation has not been adopted outside of Manitoba.

Other experimental plans include Windy Bay, which chose to layout its residences in a herringbone arrangement. This option has also been adopted by Bigstone Colony, and its 


\section{Figure 11: Examples of Innovative Colony Plans among the Schmiedeleut (Bloomfield, Starlight, Norquay, Lismore)}
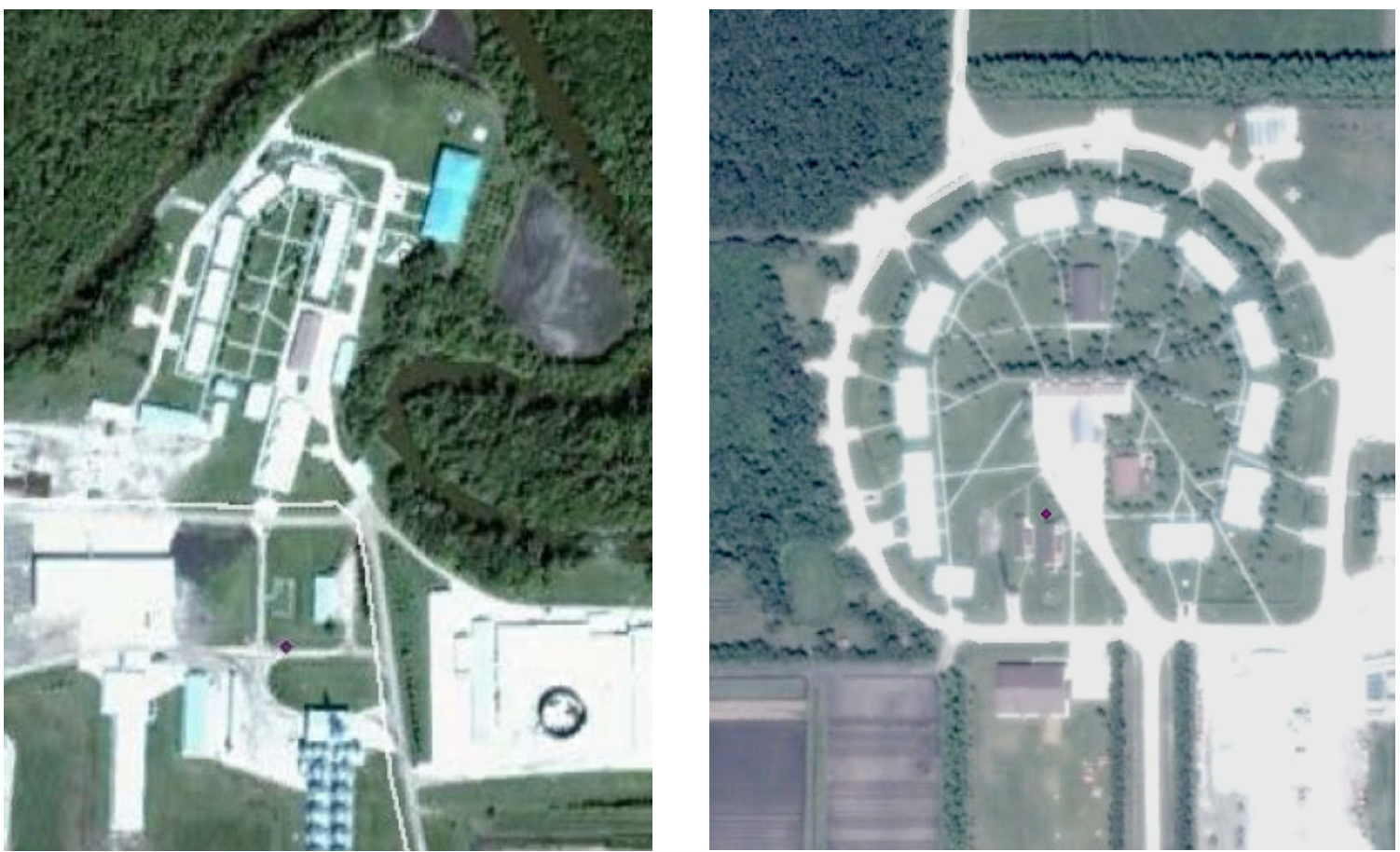

Left: Bloomfield Colony, Manitoba, S2, founded 1957. The residential area is tucked into a meander of the

Whitemud River. Image: Google Earth, 2013, DigitalGlobe. Right: Starlight Colony, Manitoba, S1, founded 1991. The first colony to adopt a circular plan. Image: Google Earth, 2013, DigitalGlobe.
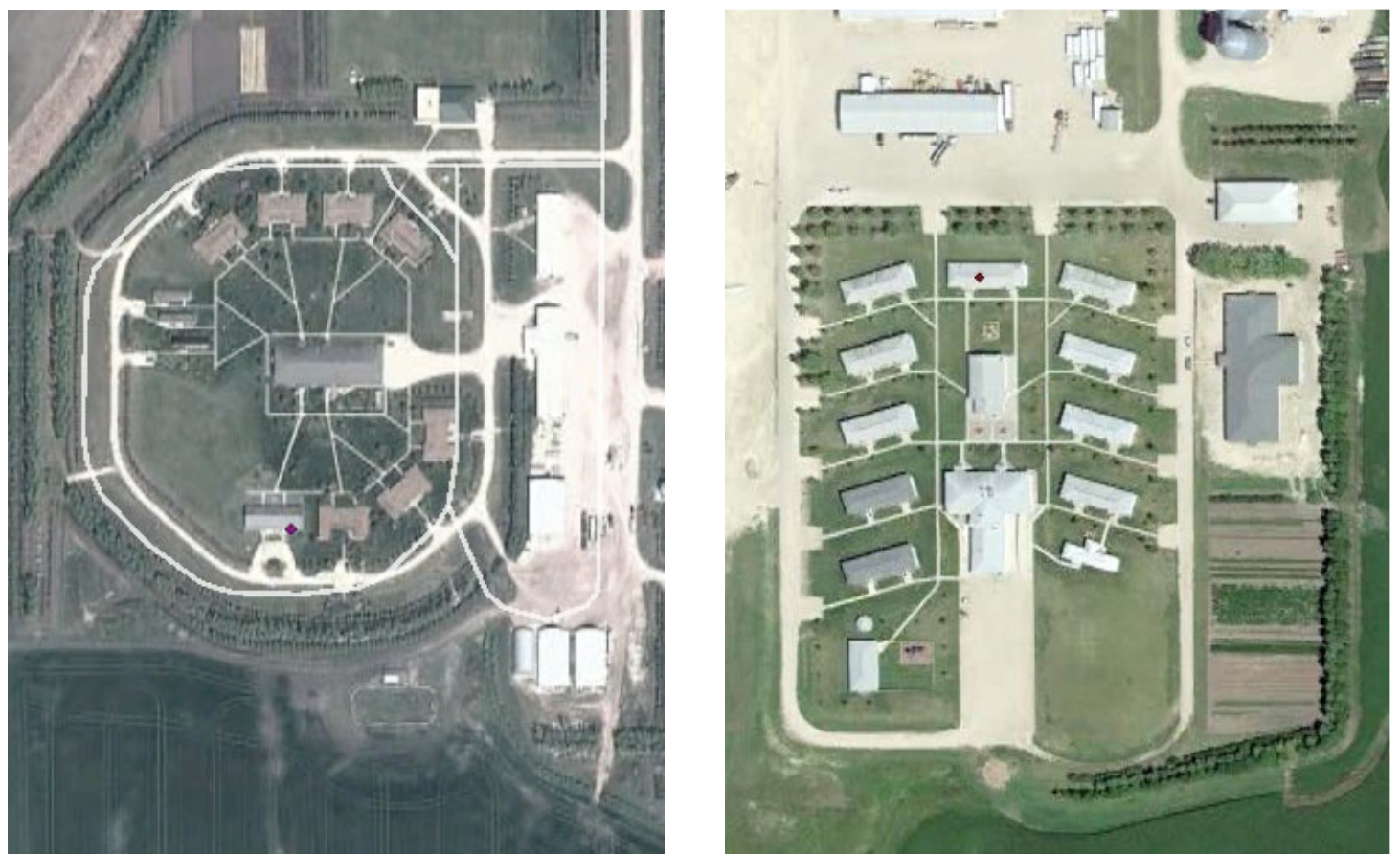

Left: Norquay Colony, Manitoba, S2, founded 1993. Another circular plan which will take a few more years to complete. Image: Google Earth, 2012, DigitalGlobe. Right: Lismore Colony, Minnesota, S2, founded 2004. The 10 duplex units are arranged in a herringbone fashion. Image: Google Earth, 2015. 


\section{Figure 11: Some Unusual Colony Plans (King Ranch, Sunnyside, Prairie Elk, Ridge Valley)}
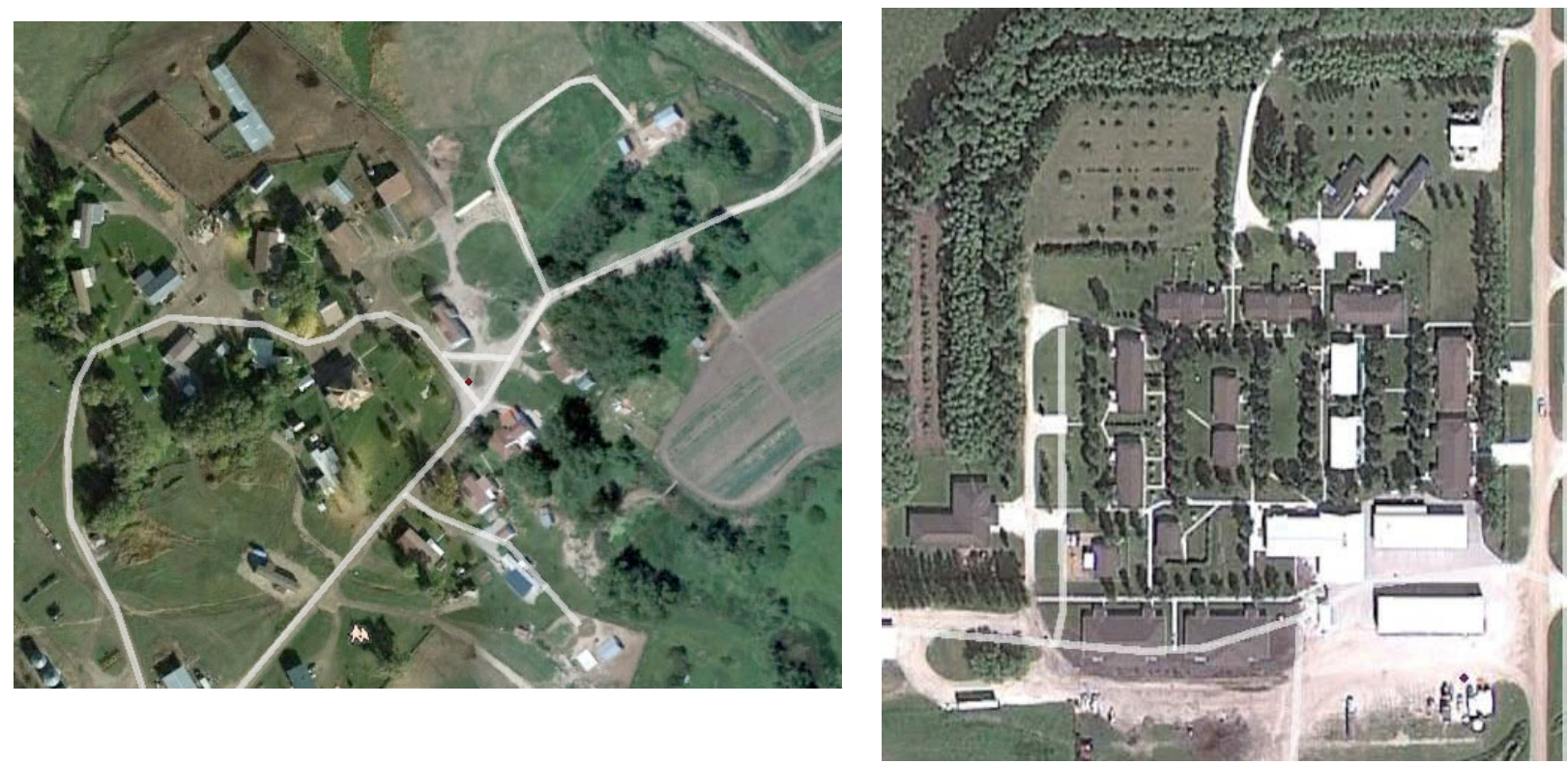

Left: King Ranch Colony, Montana, Dariusleut, founded 1935. A less structured non-geometric site plan. Image: Google Earth, 2013. Right: Sunnyside Colony, Manitoba, S2, founded 1942. This colony rebuilt its housing around five courts, a radical departure. Image: Google Earth, 2009, DigitalGlobe.
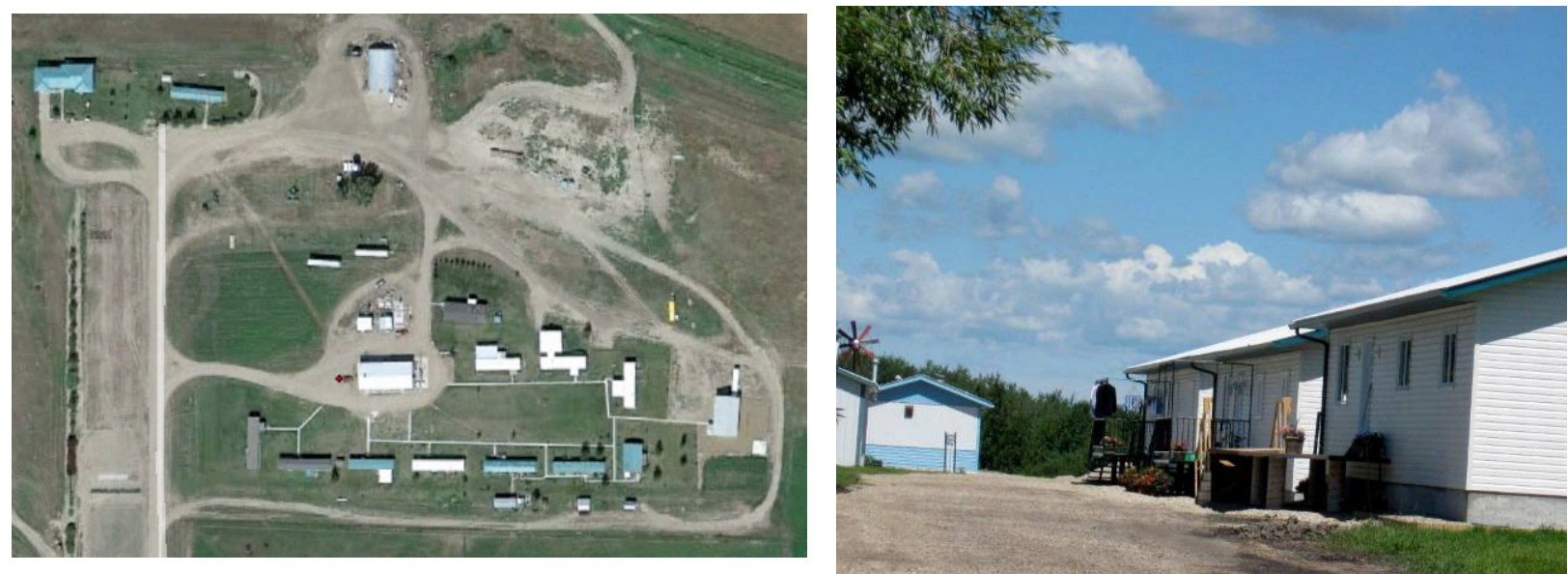

Left: Prairie Elk Colony, Montana, Dariusleut, founded 2006. Colony presently living in trailers. Image: Google Earth, 2013. Right: Single family dwellings at Ridge Valley Colony, Alberta, Dariusleut, founded 1977. Photograph by Simon M. Evans. 2013.

daughter colony Lismore in Minnesota, and by Willow Bank in North Dakota. Newdale has been even more radical with its unique star shape: long row residences pointing towards the kitchen in the centre. A final anomaly is found at Sunnyside Colony, which totally rebuilt its colony on the basis of a number of residential courts each enclosing its own patch of lawn. This plan resulted from collaboration between colony leaders and architectural student Sibylle Becker (1989, Part 3). 
The most unexpected finding of an overview of Schmiedeleut colony sites was the importance of single-family dwellings; photograph after photograph showed trailers or selfcontained bungalows. In Manitoba there are more colonies with such units than those without [53:39]. In the United States the ratio is even more biased in favour of single dwellings. This is not an entirely new development. Ryan $(1977,26)$ commented: "Some of the newer colonies have a number of single family dwellings which can easily be moved when the colony subdivides." Clearly, there are advantages to using mobile homes or prefabricated houses for Hutterite work crews as they build the infrastructure for a daughter colony. Such accommodation can also provide overflow housing as a colony grows towards its upper population limits. In addition, many colonies will adapt the original farmhouse, which came with the land, to their needs, and even haul in other nearby structures. These buildings may be demolished as the colony matures, and mobile homes can be moved to daughter colonies. Fairview Colony in North Dakota has incorporated eight older houses and four trailers into its plan. However, there is an undeniable sense of permanence about some mobile home sites on colonies, while on others custom-built bungalows make up a quarter of all the housing units available. The pristine layout of Deerfield Colony for instance includes 6 bungalows as well as 7 three-unit row houses. The growth of single-family housing has escaped notice until now, and it is a significant trend that will be discussed below.

\section{Discussion}

The first objective of this paper, to establish that Hutterite colonies constitute a significant and growing element of the humanized landscape of the Canadian Prairies and the Northern Great Plains, has been achieved by a review of the plans of all colonies and the selection of images chosen. With regard to the second objective, increasing diversity is a central theme running through Janzen and Stanton's (2010) analysis of all aspects of Hutterite life. This paper provides evidence of yet another way in which Hutterite society is becoming more complex and variegated. Differences, both between clan groups and within each leut have been revealed and described. The new landscape element - the Hutterite colony — is by no means a monolithic homogeneous entity.

Most colonies were laid out carefully according to a preconceived plan. In the case of the Lehrerleut, their colonies are almost exactly the same, and plans for new colonies have to be approved by a committee to ensure uniformity. The majority of Dariusleut and Schmiedeleut colonies also conform to simple geometric grid patterns, although there is more variety in detail. The kitchen complex is the functional center of the colony, and efforts are made to insure that all residential units have much the same access to this facility. During the past few decades, free standing churches have been built on many Dariusleut and Schmiedeleut colonies, while the Lehrerleut have added a simple church room to their kitchen complex.

Innovative configurations for the dwellings in the headquarters sites of both Dariusleut and Schmiedeleut colonies are becoming more common. In Manitoba, a significant proportion of 
daughter colonies have adopted circular sites. In Alberta, many new colony sites are diamond or arc shaped. What does this flurry of innovation and experimentation mean? Leaders of these colonies with non-traditional designs are quick to point out that they make the kitchen complex more exactly equidistant from each residential unit, and thus enhance the basic principle of equality between the colony members. However, these new plans clearly signal a rejection of the old and familiar and an unwillingness to be bound by the status quo. Some observers, both Hutterites and outsiders, suggest that these departures are motivated by hubris and the desire to show off both wealth and ingenuity. There may be an element of truth in these criticisms. Becker $(1989,137)$, commenting on the radical circular design adopted by James Valley colony for their daughter colony Starlight, said, "It seems the mother colony made a special effort to be different, to set an example for alternative designs." Certainly, James Valley has proved to be outward looking in other spheres. It has a bookstore and an ongoing commitment to making Hutterite history known.

It seems probable that the Schmeideleut's association with the Bruderhof has played a role in their adoption of alternate forms of settlement. Anthropologist Gertrude Huntington (1993) contrasted the attitudes of several Anabaptist groups towards 'nature' in general and agricultural production in particular. She suggested that Hutterites retained a pragmatic medieval view of the natural world as being something to be subdued and made productive. On the other hand, Eberhard Arnold and his Bruderhof followers - in reaction to the industrialization and urbanization of Europe - regarded nature as pure and precious in its own right. For fifty years, Schmeideleut Hutterites interacted with the Bruderhof and moved back and forth to their settlements in the east. They must have been influenced by the aesthetic which they witnessed: flower gardens, tree bowers, and the careful placement of dwellings. Our findings suggest that this influence was pervasive. Table 2 shows that Schmiedeleut colonies have more than double the number of innovative layouts than the other clan groups.

There are other possible explanations for the growing number of innovative designs. Hutterites have shown a sophisticated ability to monitor trends in agriculture and agricultural technology in the host society. The Brethren pride themselves, with considerable justification, on being early adopters of innovations. They have demonstrated an ability to borrow ideas and machinery and then to adapt them to fit their particular needs. Perhaps some of this imaginative and creative energy is spilling over from the way Hutterites "make a living", into the more intimate sphere of how they live and organize their lives. The emergence of these dramatic new plans should not be taken out of context. It is but the latest in a series of important changes on the colonies: the move from large multi-story frame buildings to single-story homes with interior plumbing during the 1960s and 1970s; the adoption of duplexes by the Schmiedeleut; and most recently the widespread choice of both the Lehrerleut and the Dariusleut of long low 'motel style' housing during the 1990s. These quite radical steps have transformed the way Hutterite families live but have not apparently breached the integrity of the culture. New layouts will be quietly absorbed in the same way. 
The uniformity of geometric plans on the majority of colonies throws departures from the norm into stark relief. It is tempting to equate clean lines, careful planning and immaculate landscaping, with orthodoxy, efficiency and adherence to tradition. What do we make of colonies where the residences, of a variety of styles, are laid out with no obvious plan? On closer examination it becomes clear that these non-geometric colonies have a variety of different origins. Several older colonies could be labeled "colonies of accumulation". Their sites have become increasingly complex, as buildings have been added piecemeal over the decades. Standoff and Pincher Creek in Alberta, and Barrickman and Tschetter among the Schmiedeleut, are examples. Several more recently established colonies, which display no regular pattern, are "colonies in transition". Lack of resources has forced them to rely on housing scavenged from the neighbourhood and on mobile homes. Typical would be Cleardale, a Dariusleut colony in the Peace River country of Alberta established in 2001. Presently, most families are housed in assorted buildings relocated to the site and in five neatly aligned mobile homes. But already a new kitchen complex and one multi-family row house have been completed. As funds become available, so this colony will be transformed and a more regular plan will emerge. ${ }^{12}$

Finally, there is a relatively small sample of colonies that have spurned the normative desire for order. Their buildings are disposed in a random fashion and consist of a variety of housing types. In the Lewistown area of Montana, King Ranch (1935) and its daughter colonies, Ayers Ranch (1945), Surprise Creek (1963) and Flat Willow (1980), all exhibit these characteristics. It is probably significant that the founding colony of this group, King Ranch, came to Montana from Beadle, South Dakota, in 1935 during the worst of the Great Depression. Perhaps these circumstances embedded a 'hard scrabble' ethic, which has been repeated through succeeding generations. These Montana colonies may not have a geometric design or specific orientation, but they are by no means dysfunctional. They have lasted many years and have established new daughter colonies at regular intervals. Their leaders might defend their unconventional layouts by pointing out that they are less 'worldly' and adhere more closely to the ascetic ideals of the Hutterites than do their more polished and conforming neighbours. ${ }^{13}$ However, several of these colonies are very small, Ford's Creek (population 18), Kirby Butte (23), and Prairie Elk (35), and this size is not necessarily due to recent colony division. This could indicate higher than usual defection rates, or premature hiving by a family faction. These colonies deserve more detailed study.

What is the significance of the prevalence and ubiquity of single-family dwellings on colonies, particularly among the Schmiedeleut? So many families living an important part of their lives separated to some extent from the community, seems at first sight to be both a radical and negative development for the health of the sect. Living in a secluded trailer on the periphery of the residential area would surely provide a family with more privacy and less oversight, although these differences are likely to be relative rather than absolute: doors will always be open and constant "dropping in" will be expected (Becker 1989, 118; Janzen and Stanton 2010, 110). Further reflection suggests that such an evaluation may be premature. What if most of these 
units are occupied by retired couples? At two different Dariusleut colonies, the ministers showed off new single unit bungalows with some pride, and explained that they were assigned to newlywed couples. ${ }^{14}$ The expectation was that they would move into a multi-family building when they start a family. Presently, we do not know if such units are sought after by families, or if they are occupied with a sense of resignation until there is room elsewhere. Too many questions remain unanswered; a balanced evaluation of this trend will require more research.

\section{Conclusion}

The Hutterites look back proudly over 400 years of history. They have survived wars, persecution, and spiritual complacency that led to a partial abandonment of communal life. They reacted to threats by migrating across the ocean, and a remnant has always survived to rebuild the "Hutterite Way". Today, as in former times, the "Little Ark" is being buffeted both by developments in the host society and from within the sect. ${ }^{15}$ Their primary tenet of pacificism is threatened when one colony takes another to the "English courts". (Essau 2006) Their traditional forms of worship are challenged by evangelical Christians who have successfully lured away both Hutterite youths and entire families. The adoption of non-agricultural activities has drawn the Brethren into closer interaction with the host society. Cell phones and burgeoning technology are both a blessing and a curse.

During the last twenty years the rate of Hutterite population growth has slowed, and the time between colony divisions has doubled. The necessity to save for the next generation has become less urgent, and it has become more difficult for Hutterite leaders to justify to their people a tight hand on the purse strings. Increasing collective affluence, and individual demands for more consumer goods, are becoming bones of contention. But the Hutterites will face the problems posed by a new "Golden Age" with the common sense and resolution with which they have faced down hostility and persecution. There is no reason to doubt that there will be another generation of growth and a proliferation of colonies, an abiding feature of our cultural landscape.

\section{Endnotes}

${ }^{1}$ Contact information: Simon Evans, Department of Geography, University of Calgary, 2500 University Drive NW, Calgary, AB T2N 1N4, Canada; evanss@ucalgary.ca

${ }^{2}$ The kitchen plays an important role as a central meeting place on a colony, the coffee pot is always on, and workers and visitors come and go. The communal dining-room is attached, as are store rooms, a bakery, and a small room for children to eat in. Hereafter, this multi-use building will be referred to as the kitchen.

${ }^{3}$ One map can be retrieved through ArcGIS Online's interactive web map service at http://arcg.is/1Vee83o. The Google Earth version and the shapefile - used to create the ArcGIS Online version - can be downloaded from the Figshare data repository site at https://figshare.com/articles/North_American_Hutterite_Colonies_Geospatial_Level/3118162. 
${ }^{4}$ This is not a historical phenomenon, but rather an ongoing process. Twenty years ago the farm population of Alberta numbered 176,940 and made up 7\% of the province's population (Statistics Canada Agriculture Division 1992); in 2011, the corresponding numbers were 129,810 and 3.6\% (Statistics Canada 2013).

${ }^{5}$ The average time between colony splits is 30 years. This would mean 237 new colonies in the period 2010/2025, total 712 , less some defections.

${ }^{6}$ In 2011 in Alberta there were 165 Hutterite colonies and 95 Census villages (Statistics Canada 2012). The mean population of the Hutterites colonies was 95 and for the Census villages was 408. In 2011 Alberta's 15,600 Hutterites made up approximately 12\% of the total farm population - see endnote 4 (Statistics Canada 2016).

${ }^{7}$ Over the course of 40 years the senior author has visited some 125 colonies.

${ }^{8} 61$ colonies (14\%) show slight deviation from N-S or E-W orientation. Examples would be Huron and Milltown in Manitoba, and Camrose and Ferrybank in Alberta.

${ }^{9}$ Colonies of which there are images included are rendered in bold type.

${ }^{10}$ The author is referring to a 'living unit' or apartment in one of the old frame houses, which housed as many as eight families under one roof.

${ }^{11}$ The figures are: Dariusleut, 19; Lehrerleut, 26; and Schmiedeleut, 21.

${ }^{12}$ Raymore (2003) in Saskatchewan, and Haven (1989) and Neuhof (1994) in Minnesota, are other examples of colonies with plans which are still evolving.

${ }^{13}$ It is interesting that these colonies are the ones which have welcomed outsiders from the media. King Ranch was the colony explored in a long documentary by National Geographic, "American Colony: Meet the Hutterites," in 10 episodes, National Geographic Channel, 2012; while Surprise Creek was featured in an article in National Geographic (Allard 2006). It is perhaps unfortunate that such atypical colonies should be portrayed as the norm to the general public. In Alberta the focus on Standoff colony by Karl Peter and the Glenbow Museum, is rather similar (Dempsey and Spiteri (photos) 1978).

${ }^{14}$ Interviews, Sandhills Colony, June 2014, and Ridge Valley Colony, July 2013. On these occasions the topic came up in general conversation. Because I had not realized how common single-family units were, I did not make them a focus of enquiry.

15 The image of Noah's Ark is popular both on the colonies and among commentators. It is included in the title of a recent book, and several articles (Katz and Lehr 2012; Huntington 1997). 


\section{References}

Allard, William. 2006. "Solace at Surprise Creek." National Geographic (June):120-47.

Becker, Sibylle. 1989. The Hutterites: Architecture and Community. Unpublished MA Thesis, Faculty of Environmental Design, University of Calgary.

Dempsy, Hugh, and Edward Spiteri (photos). 1978. Hutterites: The Hutterite Diamond Jubilee. Calgary, AB: Glenbow-Alberta Institute.

Epp, Roger. 2005. “Two Albertas: Rural and Urban Trajectories.” Pp. 727-48 in Alberta Formed Alberta Transformed, Volume 2, edited by M. Payne, D. Wetherell, and C. Cavanaugh. Edmonton, AB: University of Alberta Press.

Essau, Alvin. 2006. Courts and the Colonies: The Litigation of Hutterite Church Disputes. Vancouver, BC: University of British Columbia Press.

Evans, Simon. 2010. "Alberta Hutterite Colonies: An Exploration of Past, Present, and Future Settlement Patterns." Communal Studies 30(2):27-64.

Evans, Simon. 1985. "Some Developments in the Diffusion of Hutterite Colonies." Canadian Geographer 29(4):327-39. http://dx.doi.org/10.1111/j.1541-0064.1985.tb00380.x

Evans, Simon, and Peter Peller. 2015a. "A Brief History of Hutterite Demography." Great Plains Quarterly 35(1):79-101. http://dx.doi.org/10.1353/gpq.2015.0013

Evans, Simon, and Peter Peller. 2015b. "The Hutterites Come to Alberta." Alberta History 63(4):11-19.

Hofer, John. 1982. The History of the Hutterites. Winnipeg, MB: W.K. Printers Aid.

Hostetler, John. 1974. Hutterite Society. Baltimore MD: Johns Hopkins University Press.

Huntington, Gertrude. 1993. "Ideology, History, and Agriculture: Examples from Contemporary North America." Culture and Geography 13(45-46):21-25.

Huntington, Gertrude. 1997. "Living in the Ark: Four Centuries of Hutterite Faith and Community," in America's Communal Utopias, edited by D.E. Pitzer. Chapel Hill, NC: University of North Carolina Press.

Hutterian Brethren. 2016. HB Directory. Retrieved May 2016 (www.hutterites.org/directory).

Janzen, Rod, and Max Stanton. 2010. The Hutterites in North America. Baltimore, MD: Johns Hopkins University Press. 
Katz, Yossi, and John Lehr. 2012. Inside the Ark: The Hutterites in Canada and the United States. Regina, SK: Canadian Plains Research Centre Press.

Kraybill, Donald, and Carl Bowman. 2001. On the Backroad to Heaven: Old Order Hutterites, Mennonites, Amish and Brethren. Baltimore, MD: John Hopkins University Press.

Manning, Richard. 2011. Rewilding the West: Restoration in a Prairie Landscape. Oakland, CA: University of California Press.

Melland, John. 1985. Change in Hutterite House Types. Unpublished Ph.D. Dissertation, Louisiana State University.

Mennonite World Conference Faith and Life Commission. 2016. Global Anabaptist Mennonite Encyclopedia Online. Retrieved May 2016 (http://gameo.org/index.php?title= Welcome_to_GAMEO).

Peters, Victor. 1976. "The Process of Colony Division among the Hutterians: A Case Study." International Review of Modern Sociology 6(1):57-64.

Popper, Frank, and Deborah Popper. 1987. "The Great Plains from Dust to Dust." Planning 53(December):12-18.

Ryan, John. 1977. The Agricultural Economy of Manitoba Hutterite Colonies. Toronto, ON: McClelland and Stewart.

Stabler, Jack. 1992. The Changing Role of Rural Communities in an Urbanizing World, 19611990. Regina, SK: Canadian Plains Research Centre.

Stabler, Jack, and M. Rose Olfert. 2005.'The Economic Structure of Saskatchewan's Communities." in Encyclopedia of Saskatchewan. Regina, SK: Canadian Plains Research Centre.

Statistics Canada. 2016. 2011 Census of Canada Topic-Based Tabulations: Selected Collective Dwellings and Population Characteristics and Type of Collective Dwelling for the Population in Collective Dwellings of Canada, Provinces and Territories. Retrieved May 2016 (http://www12.statcan.gc.ca/census-recensement/2011/dp-pd/tbt-tt/Rpeng.cfm?TABID $=2 \& \mathrm{LANG}=\mathrm{E} \& \mathrm{APATH}=3 \& \mathrm{DETAIL}=0 \& \mathrm{DIM}=0 \& \mathrm{FL}=\mathrm{A} \& \mathrm{FREE}=0 \&$ $\mathrm{GC}=0 \& \mathrm{GK}=0 \& \mathrm{GRP}=1 \& \mathrm{PID}=102239 \& \mathrm{PRID}=0 \& \mathrm{PTYPE}=101955 \& \mathrm{~S}=0 \& \mathrm{SHOWALL}$ $=0 \& \mathrm{SUB}=0 \&$ Temporal $=2011 \& \mathrm{THEME}=91 \& \mathrm{VID}=0 \& \mathrm{VNAMEE}=\& \mathrm{VNAMEF}=$ ).

Statistics Canada. 2013. CANSIM Table 004-0126: Socioeconomic Overview of the Farm Population, Population Distribution for Rural and Urban Centres of the Farm and Non-Farm Population. Retrieved May 2016 (http://www5.statcan.gc.ca/cansim/a26? lang=eng\&retrLang=eng\&id=0040126\&\&pattern $=\&$ stByVal $=1 \& p 1=1 \& p 2=50 \&$ tabMo $\mathrm{de}=$ dataTable \&csid $=$ ). 
Statistics Canada. 2012. Geosuite: 2011 Census. Catalogue No. 92-150-XBB. Retrieved May 2016 (http://www12.statcan.gc.ca/census-recensement/2011/geo/ref/geosuite-eng.cfm).

Statistics Canada Agriculture Division. 1992. Trends and Highlights of Canadian Agriculture and its People, Catalogue no. 96-303E. Retrieved May 2016 (http://publications.gc.ca/ collections/collection_2013/statcan/rh-hc/CS96-303-1992-eng.pdf). 